\title{
Sentiment in Central Banks' Financial Stability Reports
}

Correa, Ricardo, Keshav Garud, Juan M. Londono, and Nathan Mislang

Please cite paper as:

Correa, Ricardo, Keshav Garud, Juan M. Londono, and

Nathan Mislang (2017). Sentiment in Central Banks' Financial

Stability Reports. International Finance Discussion Papers

1203.

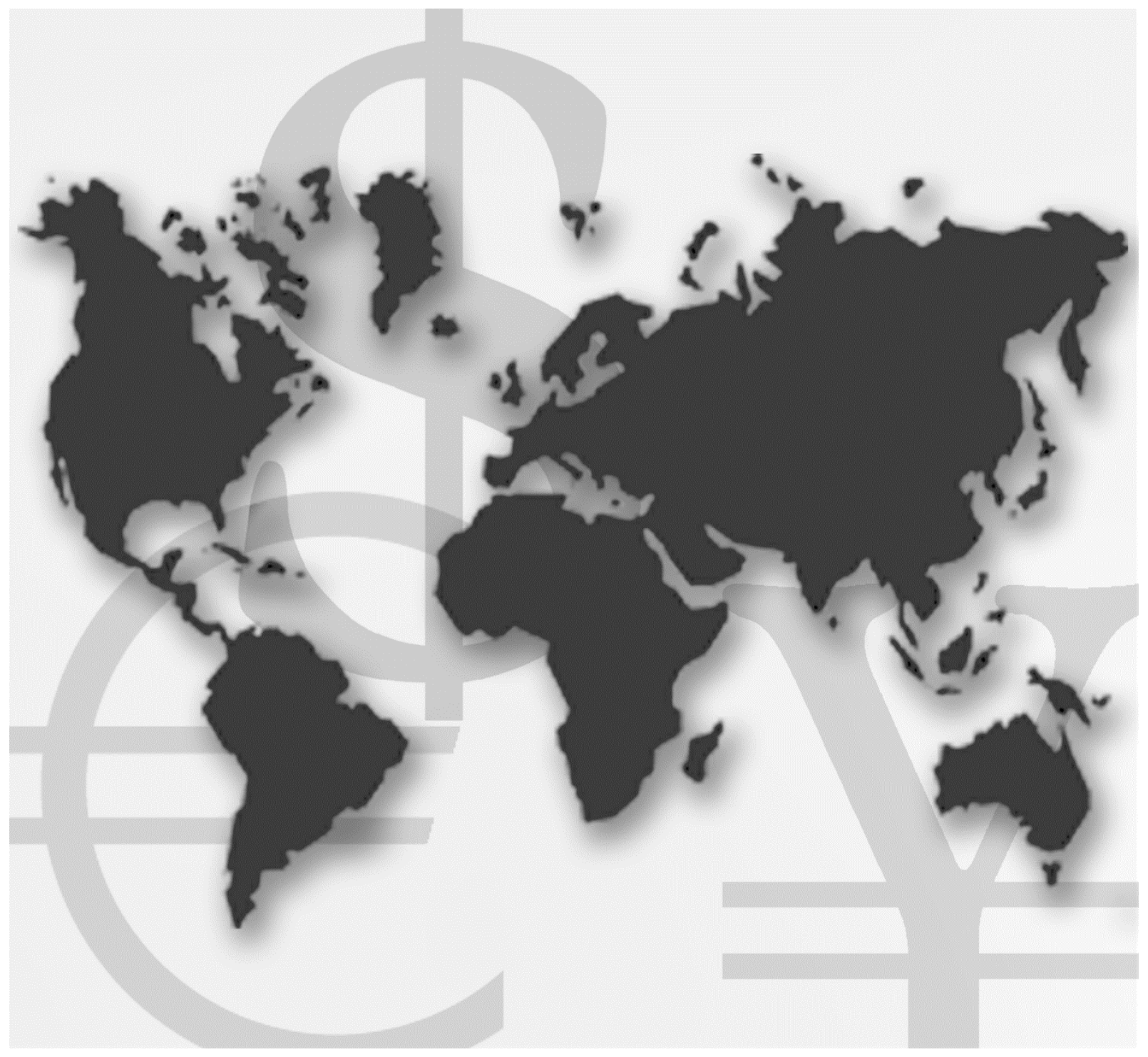

\section{International Finance Discussion Papers}

Board of Governors of the Federal Reserve System

Number 1203

March 2017 
Board of Governors of the Federal Reserve System

International Finance Discussion Papers

Number 1203

March 2017

\section{Sentiment in Central Banks’ Financial Stability Reports}

Ricardo Correa, Keshav Garud, Juan M. Londono, and Nathan Mislang

NOTE: International Finance Discussion Papers are preliminary materials circulated to stimulate discussion and critical comment. References in publications to International Finance Discussion Papers (other than an acknowledgment that the writer has had access to unpublished material) should be cleared with the author or authors. Recent IFDPs are available on the Web at https://www.federalreserve.gov/econres/ifdp/. This paper can be downloaded without charge from Social Science Research Network electronic library at http://www.sssrn.com. 


\title{
Sentiment in central banks' financial stability reports*
}

\author{
Ricardo Correa, Keshav Garud, Juan M. Londono†, and Nathan Mislang \\ Federal Reserve Board
}

April 4, 2017

\begin{abstract}
Using the text of financial stability reports (FSRs) published by central banks, we analyze the relation between the financial cycle and the sentiment conveyed in these official communications. To do so, we construct a dictionary tailored specifically to a financial stability context, which assigns positive and negative connotations based on the sentiment conveyed by words in FSRs. With this dictionary, we construct a financial stability sentiment (FSS) index. Using a panel of 35 countries for the sample period between 2005 and 2015, we find that central banks' FSS indexes are mostly driven by developments in the banking sector and by the indicators that convey information about the health of this sector. We also find that the sentiment captured by the FSS index translates into changes in financial cycle indicators related to credit, asset prices, and systemic risk. Finally, our results show that central banks' sentiment deteriorates just prior to the start of banking crises.
\end{abstract}

JEL Classification: G15, G28.

Keywords: Financial stability, Central bank communications, Text analysis, Dictionary, Sentiment index.

*We thank Daniel Beltran, Charlie Calomiris, Mark Carey, Stijn Claessens, Neil Ericsson, Matteo Iacoviello, Steve Kamin, Ellen Meade, and participants at the Federal Reserve Board workshop, the 2016 Regulatory Data Workshop, and the 2016 News and Finance Conference at Columbia University. We also thank the central banks of the following countries for providing financial stability reports not available online: Argentina, Brazil, Canada, Germany, Croatia, Singapore, Slovenia, and the United States (Financial Stability Oversight Council). The analysis and conclusions set forth are those of the authors and do not indicate concurrence by other members of the research staff or the Board of Governors.

${ }^{\dagger}$ Corresponding author. E-mail: juan-miguel.londono-yarce@frb.gov 


\title{
Sentiment in central banks' financial stability reports
}

\begin{abstract}
Using the text of financial stability reports (FSRs) published by central banks, we analyze the relation between the financial cycle and the sentiment conveyed in these official communications. To do so, we construct a dictionary tailored specifically to a financial stability context, which assigns positive and negative connotations based on the sentiment conveyed by words in FSRs. With this dictionary, we construct a financial stability sentiment (FSS) index. Using a panel of 35 countries for the sample period between 2005 and 2015, we find that central banks' FSS indexes are mostly driven by developments in the banking sector and by the indicators that convey information about the health of this sector. We also find that the sentiment captured by the FSS index translates into changes in financial cycle indicators related to credit, asset prices, and systemic risk. Finally, our results show that central banks' sentiment deteriorates just prior to the start of banking crises.
\end{abstract}

JEL Classification: G15, G28.

Keywords: Financial stability, Central bank communications, Text analysis, Dictionary, Sentiment index. 


\section{Introduction}

After the Global Financial Crisis (GFC) of 2008, policymakers around the world embarked on a series of reforms to enhance the resilience of the financial sector and to mandate financial supervisors to monitor financial stability developments. As a result, many central banks received a financial stability mandate or added financial stability to their monetary policy decision making process (Jeanneau, 2014). With this mandate, financial stability communication became an additional tool for central banks (Born et al., 2014). Announcements related to financial stability may reveal information about the condition of the financial system or about the reaction function of central banks to financial developments. However, little is known about the information and sentiment conveyed through central banks' communications of financial stability and about the response of financial cycle indicators to these announcements.

To fill this gap in the literature, in this paper, we analyze the sentiment communicated in financial stability reports (FSRs), one of the main tools used by central banks to disseminate their views on financial stability developments. We first propose a financial stability text analysis dictionary that captures the sentiment conveyed by words typically used in financial stability communications. We then use this dictionary to calculate a financial stability sentiment (FSS) index based on the text from FSRs published by central banks and multilateral organizations. Finally, we explore how information is incorporated in the FSS index and test whether central bank communications, as captured by the FSS index, have predictive power for future movements of financial cycle indicators and for the development of banking crises.

The FSS index is calculated as the relative proportion of negative to positive words in financial stability documents. To determine whether each word has a positive or negative connotation, we construct a text analysis dictionary tailored specifically to the financial stability context. Our dictionary is constructed using words from the FSRs of 62 countries, the European Central Bank (ECB), and the International Monetary Fund (IMF) published 
between 2000 and $2015 .^{1}$

For the purpose of analyzing sentiment in financial stability communication, our dictionary is a refinement of general dictionaries proposed in the literature, such as Harvard and IV-4, and of finance-specific dictionaries, such as that in Loughran and McDonald (2011) (LM hereafter). Our dictionary contains 391 words, of which 96 are positive and 295 are negative. Our word classification suggests that words can have a different connotation in a financial stability context. Specifically, we find that, although there is considerable overlap between our dictionary and that in LM, over 30 percent of the positive or negative words in our dictionary are not classified in LM's dictionary.

FSRs have become increasingly popular among central banks in the past 20 years. These reports are used to communicate risks and vulnerabilities in the financial system and are also meant to increase the transparency of central banks. The Bank of England was, as far as we are aware, the first central bank to have published an FSR in 1996 (see also Born et al., 2014; Osterloo et al., 2011). By 2005, 35 institutions were publishing versions of their FSRs in English.

Using our dictionary, we calculate the FSS index from the text in FSRs. In broad terms, we find that the cross-country average FSS index increases considerably around the peak of the GFC and then again around the peak of the euro-area sovereign debt crisis in 2012. There are, however, important differences in the dynamics of FSS indexes across countries. For instance, while the FSS index of some countries increases after crisis episodes, sentiment seems to deteriorate earlier for others.

Because sentiment is an unobservable characteristic of FSRs that could be mismeasured, we conduct a set of robustness tests to assess the stability of our index and our dictionary. In particular, we calculate confidence intervals for the sensitivity of the FSS index to the words in the dictionary. To do so, we perform an iterative procedure in which we randomly remove a portion of the words in the dictionary and recalculate the index. We find that relatively

\footnotetext{
${ }^{1}$ We collect only FSRs published in English, as our dictionary only classifies words in this language.
} 
small variations in the dictionary have minimal effects on the dynamics of FSS indexes.

We formally test the patterns in central banks' communications by following a multi-step strategy using the FSS indexes of the 35 countries with at least one FSR between 2005 and 2015. In the first step, we analyze the topics driving the FSS index and how information about specific sectors of the economy is incorporated in the FSS index. In a second step, we assess the financial cycle indicators that drive central banks' sentiment on financial stability and, conversely, whether changes in the FSS index lead to changes in future realizations of these financial cycle indicators. In this same vein, in a third step, we study whether central banks' sentiment deteriorates prior to banking crises.

We analyze central banks' focus on particular sectors or topics to understand the information set used by these institutions to determine their overall financial stability communication strategy. For this purpose, we calculate a set of topic-specific sentiment indexes. These indexes are produced using a subset of sentences in FSRs that relate to one of the following topics: banking, asset valuations, household, real estate, corporate sector, external sector, and sovereign sector. We find that, although most topic indexes significantly drive the time variation in the FSS index, concerns about the banking sector are the main driver of the overall FSS index at the country level.

After analyzing the relative importance of topic-specific indexes for the overall financial stability assessment of central banks, we investigate how information from financial indicators drives these topic indexes. This exercise provides evidence on the reaction function of central banks, at least on the communications front, to developments in financial indicators. For each of the topic indexes, we assess the relation between the sentiment conveyed and quantitative indicators of developments in those sectors. We find that information in topic-specific quantitative indicators is incorporated in topic-specific sentiment indexes. In particular, a deterioration of financial indicators is, in general, followed by a significant deterioration in central banks' financial stability sentiment.

We then study the relation between central banks' overall sentiment about financial 
stability and financial cycle variables related to credit, asset prices, and systemic risk. As with topic indexes, we first test how information from financial cycle indicators is incorporated in the FSS index and, conversely, whether the communicated sentiment correlates with future realizations of these financial cycle indicators. Although an analysis of the specific channels through which communications affect financial cycle variables are beyond the scope of this paper, we believe that testing for the significance of this relation is an important contribution to the literature on central banks' communications. We find that financial cycle characteristics and sentiment about financial stability jointly influence each other.

To account for this endogeneity between FSS and the financial cycle, we propose a panel vector autoregressive (VAR) model in which the dependent variables are the FSS index and each one of the variables characterizing the financial cycle. We find that a deterioration in sentiment about financial stability is followed by a significant deterioration of most financial cycle indicators. In particular, an increase in the FSS index is followed by a significant increase in the debt service ratio, a drop in asset prices, and an increase in systemic risk. We perform a comprehensive set of tests to assess the robustness of our results. We show that the effect of the FSS index on financial cycle indicators remains significant after controlling for risk aversion, using a sample including only early publishers of FSRs, or considering alternative dictionaries. We also explore two extensions of our FSS index: a negative index and an excitement index. The results from the panel VAR imply that central banks are able to incorporate information from financial developments into their communication products, and, at the same time, they are able to foresee future developments in those financial indicators.

More than analyzing regular developments in the financial cycle, central banks should be attuned and prepared to determine turning points in the financial cycle, especially those driven by crises. To explore this, we use a panel-data probit model to investigate whether central banks are able to assess and communicate the vulnerabilities surrounding turning points in the financial cycle, especially before banking crises. We find evidence that the 
sentiment communicated in FSRs is a useful predictor of banking crises. Although the coefficient associated with the predictive power of the FSS index is borderline significant, the predictive power of the FSS index for banking crises is slightly stronger than the predictive power of the credit-to-GDP gap and the debt service ratio, two commonly used predictors of banking crises (Drehmann et al., 2015). This finding provides preliminary evidence that central banks are aware and communicate that financial stability concerns are increasing prior to a crisis. Our evidence for the predictability of banking crises is relatively weak, potentially because our short sample includes very few crisis episodes, which reduces the power of the test, and because central banks might decide to center the attention on communicating the resilience of the financial sector rather than the risks around crisis episodes, which could have contradictory effects on the FSS index. Although more work is needed to understand central banks' communication strategy, the fact that the FSS index is a better predictor than commonly used early-warning measures suggests that the information communicated by central banks may be a useful predictor of turning points in the financial cycle.

\subsection{Related literature}

Our paper contributes to the literatures on central bank communications and textual analysis applied to financial stability. Text analysis techniques have been extensively used in finance. A survey of these methods and finance applications can be found in Kearney and Liu (2014).

In the context of textual analysis techniques, the method we use to calculate our FSS index is a dictionary-based approach, which is a natural choice for long and complex documents like FSRs. Alternative text analysis methods, such as machine-learning approaches, require some type of classification that would help in categorizing text depending on pre-specified categories, which does not apply to this form of communication. In addition, because of the length of FSRs, it would be difficult to manually impose a document-level classification. Such a classification would have many more words than observations, posing a dimensionality problem for machine-learning models. 
While general dictionaries, such as Harvard IV-4 and Diction, have been used extensively in the literature to analyze word tonality, these dictionaries might not be suitable to assess the sentiment conveyed by documents in more topic-specific contexts. Henry and Leone (2016) compare the Harvard IV-4 and Diction dictionaries with that developed by Henry (2006, 2008), which is designed specifically for financial disclosure. They find that contextspecific dictionaries yield scores that are more closely related to financial market reactions to news. Also, Loughran and McDonald $(2011,2016)$ find that general dictionaries do not provide sufficient accuracy for tonality in finance contexts. ${ }^{2}$ LM create a dictionary tailored to the context of $10-\mathrm{K}$ reports and find that almost three-fourths of the words in the Harvard dictionary have a different connotation in finance. In this paper, we introduce a dictionary tailored to financial stability communications, as we show that a large portion of words have different connotations in a financial stability context compared to a general or even to a finance context.

The literature on central bank communications has mostly focused on announcements related to monetary policy (see, for instance, Blinder et al., 2008; Ericsson, 2016; and Stekler and Symington, 2016). Recent studies in this strand of the literature have used text analysis techniques to determine the effect of central banks' monetary policy communications on asset prices and real variables (Hansen and McMahon, 2016; Hubert and Labondance, 2017). However, central banks' communications on financial stability have garnered less attention. Cihak et al. (2012) and Cihak (2006) do a qualitative assessment of FSRs. Osterloo et al. (2011) explore the effect of the publication of FSRs on a set of business and financial cycle characteristics.

The closest paper to our study is Born et al. (2014), which analyzes the effect of central banks' financial stability communications on stock returns. Born et al. (2014) extract the sentiment conveyed by the executive summaries of FSRs and news articles describing interviews and speeches by central bank officials to test whether the tonality of these com-

\footnotetext{
${ }^{2} \operatorname{Li}(2010)$ also compares several dictionaries using a machine-learning approach.
} 
munications has an effect on equity prices. They find mixed results, with "optimistic" FSRs having the most significant effect on abnormal stock returns. Our paper differs from Born et al. (2014) in two key aspects. First, as noted before, our study develops a new financial-stability-specific dictionary to capture the positive or negative sentiment expressed in communications focused on that topic. In contrast, Born et al. (2014) relies on Diction, a general-purpose text analysis tool that classifies words as optimistic or pessimistic. As noted before, general dictionaries may not accurately capture the sentiment of very specific topics, such as financial stability. Second, the aim of Born et al. (2014) is to analyze the immediate effect of financial stability communications on stock returns. Our aim is to test whether changes in financial vulnerabilities affect the sentiment conveyed by the FSRs or, conversely, whether central bank communication through FSRs affects the path of financial vulnerabilities. This analysis provides additional information on the role of FSRs as a central bank communication tool.

The rest of the paper is organized as follows. Section 2 introduces the financial stability dictionary. Section 3 explains the method used to construct the FSS index. Section 4 explores the relation between the FSS index and the financial cycle. Section 5 concludes.

\section{A dictionary for financial stability analysis}

In this section, we introduce a dictionary tailored to the financial stability context. Our dictionary is created using words from the FSRs prepared by 62 countries' central banks, the ECB, and the IMF. ${ }^{3}$ In the first part of the section, we discuss the availability and general structure of FSRs. In the second part, we explain in detail the method used to create our financial stability dictionary. This dictionary is used to calculate the FSS index introduced in section 3 .

\footnotetext{
${ }^{3}$ The institution directly in charge of preparing the financial stability report in the United States is not the Federal Reserve Board, the country's central bank, but the Financial Stability Oversight Council (FSOC).
} 


\subsection{Financial stability reports}

Our dictionary is created using words from FSRs either originally written in or translated into English. Table 1 summarizes the availability of these FSRs. FSRs for all countries in our sample are available online through the website of each country's central bank. Over half of the 64 institutions publishing FSRs do so on a biannual frequency, while the rest publish reports annually. Publishers are located predominantly in Europe, with a fairly even mix of advanced and emerging-market economies in our sample. Although the central banks of England, Sweden, and Norway started publishing FSRs as early as 1996 (Born et al., 2014), regular publication started in these countries between 1999 and 2000. Other early publishers of FSRs include the IMF (2002), Austria (2001), Belgium (2002), Brazil (2002), Canada (2002), Denmark (2002), Hungary (2000), and Spain (2002). By 2005, 35 institutions were publishing FSRs. Most other institutions began publishing reports around the collapse of Lehman Brothers in September of 2008.

To create our dictionary, we have collected 982 FSRs published between 2000 and 2015. Reports in our sample have a mean length of 94 pages, with the 90 percent interval around the mean spanning from 38 to 184 pages. The contents of FSRs are heterogeneous across the sample, but most of their sections can be classified into the following categories: summary or overall assessment, domestic sector, global sector, financial sector, special topics, and payment systems. ${ }^{4}$ We filter out text from special topics and payment system sections, as they are often theoretical in nature or unrelated to the financial stability outlook. We do not consider reports that focus on special topics, such as those by France.

All FSRs are available in PDF format. To analyze the text, we first preprocess the PDF documents using the PDFMiner package available for python, which converts the programmatic rendering of text in PDF documents into plain text or other formats. We convert the text in FSRs into html format because this format includes tagging that allows us to ignore

\footnotetext{
${ }^{4}$ See Cihak et al. (2012) for more background and a broader qualitative assessment of FSRs.
} 
text in titles, footnotes, and boxes with further processing.

\subsection{Methodology for creating the dictionary}

As suggested by LM and Henry and Leone (2016), words might have different connotations depending on what context they are being used in. We show that a considerable proportion of words used in FSRs have a different connotation compared to a general context or even to finance contexts, such as $10-\mathrm{K}$ reports. There are three main reasons why connotations in financial stability can differ from those in existing general or finance-specific dictionaries. First, words often convey a different sentiment in a financial stability context. For instance, the word "confined" is classified as having a negative connotation in other dictionaries but almost always conveys a positive sentiment in a financial stability context, as it refers to limiting negative spillovers. Second, words that have a positive or negative connotation in other dictionaries might be used mostly as part of technical terms in a financial stability context, as is the case of words such as "default," which is mostly used in a financial stability context for "credit default spreads," or "delinquency," which is usually used for "delinquency rates." By themselves, however, "default" and "delinquency" do not really drive sentiment in a financial stability context. The third reason our financial stability dictionary is distinct from its predecessors is because words that traditionally have a connotation are used to describe historical events, not to convey sentiment. An example of a word in this category, and widely used in FSRs in our sample, is "crisis," which is classified as negative in previous dictionaries but is mostly used to refer to the 2008 GFC. However, the word "crisis" does not usually drive sentiment for the FSRs in our sample.

To create our financial stability dictionary, we process the text from FSRs and extract individual words. To do so, we first strip the financial stability texts of all punctuation. Next, we delete stop words, such as "and," "the," and "of." We then select the top 98 percent of the remaining words by frequency across all FSRs in our sample, which amounts to 7,388 words. ${ }^{5}$

\footnotetext{
${ }^{5}$ The remaining 2 percent of words by frequency amount to 34,579 words, of which 27,219 words are used
} 
We then remove words that obviously convey no sentiment, such as "vehicle," "study," and several other nouns that refer to topics completely unrelated to financial stability. The remaining 1,484 words are classified into categories of either positive, negative, or neutral connotation.

To determine each word's connotation, we randomly choose 25 sentences that include each word from across all FSRs. Each word with its respective sentences is then independently classified by two readers. Words in disagreement between readers in this first classification are discussed in depth between the two initial readers. If disagreement remains, the words are discussed with an additional team formed by two other readers.

Table 2 reports the distribution of words in our financial stability dictionary. ${ }^{6}$ The iterative word classification process results in 96 positive and 295 negative words. Positive and negative words combined account for 5.38 percent of all distinct words in FSRs, and, in terms of frequency of use, they account for 1.45 and 2.56 percent, respectively. Another interesting conclusion from our classification process results from comparing the words in our dictionary with those in LM's dictionary. We find that, while there are similarities between the two dictionaries - 270 words are classified in both dictionaries - almost 31 percent of all positive or negative words (121 words in total) are unique to financial stability. The uniquely financial stability words represent 1.67 of all distinct words in FSRs and 0.73 percent of the frequency of use across all FSRs.

\section{A sentiment index for financial stability}

In this section, we introduce the FSS index. In the first part, we explain the method used to calculate the index using the dictionary described in section 2. In the second part, we explore the sensitivity of the FSS index to the words in the dictionary.

five or fewer times in all 982 reports. Thus, the lowest 2 percent of words correspond to very specific (often regional) uses of language or are only found in few reports, making them impractical to apply to a broader financial stability context.

${ }^{6}$ The entire dictionary can be found in the online appendix. 


\subsection{The FSS index}

For each FSR, the FSS index is calculated as follows:

$$
F S S \text { index } x_{\text {country,period }}=\frac{\# \text { Negative words }-\# \text { Positive words }}{\# \text { Total words }},
$$

where the negative or positive connotation of words is obtained from the financial stability dictionary introduced in section 2. The number of total words corresponds to all words in each FSR after removing stop words. The number of total words is related then to the total word frequency rather than to the number of distinct words in FSRs. As in LM, we negate positive words within three words of "not," "no," "nobody," "none," "never," "neither," and "cannot." However, we do not negate negative words, as double negations do not necessarily convey positive sentiment. According to equation (1), an increasing FSS index indicates that the number of negative words relative to the number of positive words increases, therefore increasing negative sentiment, or reflecting a deterioration in sentiment.

Table 3 shows a set of summary statistics for the FSS indexes for all countries in our sample, and figure 1 shows their demeaned time series. Although we calculate individual FSS indexes across all countries and periods in our dataset, for the remainder of the paper, we focus on the FSS indexes for the 35 countries in our sample with FSRs available at least once a year between 2005 and 2015 (see table 1). This reduced sample of countries allows us to compare the indexes for a homogeneous time period. Moreover, restricting the sample to countries with FSRs available for at least 10 years increases the reliability of the empirical exercise in section 4, especially because most countries not included in this sample began publishing FSRs around the 2008 GFC.

The information in table 3 shows that, other than Argentina and Malaysia, all countries' reports have a positive mean FSS index, indicating a relatively negative sentiment in our sample. FSS indexes display considerable time variation, with standard deviations ranging from 0.47 (Germany) to 1.30 (Denmark). In particular, as can be seen in panel (a) of figure 
1, all countries' FSS indexes became higher (more negative sentiment) in the period around the failure of Lehman Brothers in September of 2008. In fact, for 25 countries and the ECB, the maximum FSS index realization occurred within one year after the collapse of Lehman Brothers. Interestingly, for Chile (December 2007), Germany (November 2007), and the United Kingdom (October 2007), the maximum FSS index occurs within one year before the collapse of Lehman Brothers. All countries' indexes also became higher leading up to the second negotiation of the bailout of Greece's sovereign debt by euro-area authorities in the first quarter of 2012, and six of the European countries in our sample and the IMF experienced their highest FSS index within one year of this event.

Panel (b) of figure 1 shows the FSS indexes for the ECB and IMF reports, which are not included in panel (a). As can be seen from the figure, although both indexes remained relatively high around the failure of Lehman Brothers and then again around negotiations of Greece's second bailout, the IMF FSS index became higher earlier than the ECB index in both episodes. On average, the IMF FSS index is higher and more volatile than the ECB FSS index - the mean IMF FSS index is 2.56 percent and its volatility is 0.94 percent, compared to a mean 1.95 percent and a standard deviation of 0.85 percent for the ECB FSS.

\subsection{Sensitivity to the dictionary}

We now investigate the robustness of the method used to calculate the FSS index. In particular, we investigate the sensitivity of the index to the set of words in the financial stability dictionary. To do so, we calculate confidence intervals for the FSS index by randomly removing words from the financial dictionary at three levels: 5, 10, and 20 percent. We then calculate the FSS index with the remaining words in the dictionary and repeat the process of randomly removing words from the dictionary and calculating the FSS index 1000 times. Each time, the indexes are multiplied by a correction factor so that the levels are of comparable magnitude. This correction factor is necessary because removing words from the dictionary reduces the numerator of the FSS index (see equation (1)), essentially watering 
down the index.

To get an idea of the width of the FSS index confidence intervals after removing words from the dictionary, figure 2 shows the index's 90 percent confidence interval for a selected set of countries or regions. The figure shows that, even if one out of every five words in the dictionary were misclassified, the contours of FSS indexes are largely preserved. This evidence is robust across countries and suggests that relatively small choices and disagreement in the dictionary formation process have a minimal effect on the dynamics of FSS indexes. In unreported results, we find that, for all countries in our sample, indexes and their confidence intervals vary enough to pass a simple test of time variation. Specifically, in no country can a horizontal line be drawn that is contained in the FSS index 90 percent confidence interval, even if 20 percent of words are removed from the dictionary. ${ }^{7}$

In sum, in this section we find that, although there are important differences in the dynamics of FSS indexes across countries, sentiment turns particularly negative in episodes of crisis. We also find that the method used to calculate the FSS index is robust in that the dynamics of the index are preserved even after removing a large portion of the words in the dictionary.

\section{The informational content of the FSS index}

In this section, we investigate the informational content of the sentiment conveyed by central banks through FSRs. In the first part, we explore the sectors and topics that drive financial stability sentiment and how quantitative information is incorporated in the sentiment related to these topics. In the second part, we explore the relation between the FSS index and the financial cycle and whether the FSS index is a useful predictor of banking crises.

\footnotetext{
${ }^{7}$ Our method to test the robustness of the dictionary is similar to the method in Jegadeesh and Wu (2013). The main difference is that their method removes words from the dictionary controlling for frequency of use. In unreported results, we have calculated confidence intervals by dropping 50 percent of words using the method in Jegadeesh and $\mathrm{Wu}$ (2013). Our main results that the contours of FSS indexes are preserved remain unchanged.
} 


\subsection{Topics driving financial sentiment}

Although the FSS index is an overall measure of the sentiment conveyed in FSRs, the index does not identify the topics driving the changes in sentiment. The structure and topics of FSRs vary greatly across countries and over time, which makes it difficult to manually categorize sections within FSRs or to perform (unsupervised) topic mining on the corpus of these reports. To understand how central banks use information to determine their financial stability communication strategy, in this subsection, we analyze central banks' focus on particular sectors or topics.

As a first step to understand the focus of FSRs on different topics over time, we plot a word cloud in figure 3 with the most frequently used words in these reports for the following years: $2004,2008,2012$, and 2015. In the figure, the size of the words indicates the frequency of use across all FSRs; that is, larger words have a larger count in a particular period. The top right quadrant shows the most frequently used words in 2004, a period that could be considered to have low financial stress. This stress level is reflected in the sparsity of word use, with no fundamental topic driving the narrative in the FSRs. In contrast, FSRs published during the GFC in 2008 have a defined focus centered around the words "credit," "financial," "losses," "market(s)," "subprime," and "turmoil." All these words clearly reflect the areas most affected by the crisis, which initially was centered around the housing market in the United States and later spread to global financial markets. A similar pattern is observed in 2012, around the European sovereign debt crisis, but with the emphasis shifting to the banking and sovereign sectors. In the last quadrant, which shows the most frequently used words in 2015, the intensity of word use decreases, as in 2004, but discussions in FSRs are focused on monetary and regulatory policies and their effect on different sectors, as well as on the oil and commodity markets. The evolution of the narratives adopted in FSRs is crucial for understanding the topics and sectors driving the FSS index and the underlying vulnerabilities in each country. 
To formally analyze the patterns suggested by the word cloud, we calculate a set of topic-specific FSS indexes. The topics selected are based on a review of the literature on early-warning indicators used by central banks and multilateral organizations to assess financial vulnerabilities (see, for instance, International Monetary Fund, 2010). Each topic index is calculated using only those sentences in FSRs containing words that are related to a specific topic. Table 4 shows the words used to identify each sector. These words are selected taking into account the frequency in which they are included in FSRs as well as a manual analysis of the context in which they are mentioned. For each country and topic, the index is calculated as in equation (1) using only the portions of FSRs that contain sentences with the words in table 4.

To explore the drivers of financial sentiment, we estimate the following panel-data regression for the overall FSS index as a contemporaneous function of the topic indexes:

$$
F S S_{i, t}=u_{i}+\sum_{j=1}^{S} B_{j} F S S_{i, t}^{j}+\sum_{j=1}^{S} C_{j} F r e q_{i, t}^{j}+e_{i, t},
$$

where $F S S_{i}$ represents each country's FSS index and $F S S_{i}^{j}$ is the FSS index for topic $j$ for country $i$. We control for the frequency at which each topic's words are used in each report $\left(F r e q_{i}^{j}\right)$, as movements in topic indexes might be partially explained by the density of words from the financial stability dictionary used within those sentences. The panel data are calculated at the quarterly frequency, and the quarter assigned to each FSR corresponds to the quarter in which the report was made available. Because FSRs are published at a biannual or annual frequency, we assume a step function to interpolate between any two dates when reports are available. The coefficients are estimated using pooled ordinary least squares in which the coefficients associated with the topic indexes are restricted to be homogeneous across countries. We standardize the indexes to compare the magnitude of the estimated coefficients across topics.

The estimates of the coefficients associated with the topic indexes in equation (2) are 
shown in table 5. All topic indexes, except the one associated with the sovereign sector, are significant in explaining the time variation in the overall FSS index, at least at the 5 percent confidence level. The banking topic, with an estimated coefficient of 0.48 , drives most of the time variation in the overall index, followed by household (0.19), asset valuations (0.18), corporate (0.15), external (0.13), real estate (0.08), and sovereign (0.03).

We now investigate how information from quantitative indicators is incorporated into the FSS topic indexes. To do so, we propose the following panel-data regression setting in which topic-specific quantitative indicators explain the time variation in each topic index:

$$
F S S_{i, t}^{j}=u_{i}+\beta X_{i, t-h}^{j}+e_{i, t}
$$

where $X_{i, t-h}^{j}$ is each one of the lagged topic-specific variables defined in appendix A. The results are summarized in table 6 .

We find that bank-related indicators are contemporaneously correlated with the bank FSS index. In particular, a deterioration of these indicators - an increase in the SRISKto-GDP ratio, bank CDS spreads, credit-to-GDP gap, and debt service ratio for private nonfinancial corporations - is accompanied by a deterioration of sentiment with respect to the banking sector. This relation between bank-related indicators and the FSS bank index remains significant, at least at the 10 percent level, when quantitative indicators are lagged by one quarter. At the four-quarter horizon, the relation with the bank index becomes insignificant for all indicators considered.

The relation between the household FSS index and the debt service ratio for households is positive and significant (at least at the 5 percent level) for all horizons considered - a deterioration in the debt service ratio is accompanied and followed by a deterioration of sentiment related to the household sector. For the stock valuation topic, an increase in volatility or a reduction of stock market prices relative to either book values or dividends paid is related to a deterioration in sentiment (significant at the 1 percent confidence level for volatility at the one- and four-quarter horizons, and not significant for the dividend yield 
at the four-quarter horizon).

The relation between the corporate FSS index and the debt service ratio for private nonfinancial corporations is positive and significant for all horizons considered at any standard confidence level. For the external sector topic, the relation is only significant for currency volatility contemporaneously and at the one-quarter horizon - an increase in currency volatility is followed by a deterioration in sentiment about the external sector. However, information from macroeconomic indicators, such as current account balances or external debt, does not seem to affect significantly changes in sentiment about the external sector. For the real estate sector, a reduction in real and nominal property prices is accompanied by a significant deterioration of sentiment related to this topic, but the relation is not significant for the one- and four-quarter horizons. Interestingly, however, an increase in prices relative to rents is followed by a significant deterioration of real estate sentiment at the one- and four-quarter horizons at the 10 percent confidence level. Finally, for the sovereign sector, a deterioration of sovereign CDS and government debt to GDP is accompanied by a significant deterioration of sentiment related to this sector, and this relation remains significant at the 1 percent confidence level for the one-quarter horizon for sovereign CDS spreads.

\subsection{Financial stability sentiment and the financial cycle}

We now explore the relation between sentiment in FSRs and the financial cycle. To characterize each country's financial cycle, we use variables related to credit growth, asset valuations, and systemic risk. ${ }^{8}$ The variables considered are explained in detail in appendix A. In the

first step, we use a panel-regression setting to investigate the contemporaneous and lead-lag relations between the FSS index and each one of the variables characterizing the financial cycle. In the second step, we consider a panel VAR to account for the endogeneity between financial cycle variables and the FSS index. In the final step, we investigate the predictive power of the FSS index for banking crises.

\footnotetext{
${ }^{8} \mathrm{Ng}(2011)$ and Hatzius et al. (2010) provide a survey of financial cycle measures.
} 


\subsubsection{Lead-lag relations}

We explore the contemporaneous and lead-lag relations between the FSS index and each one of the financial cycle characteristics. To explore how information from financial cycle indicators is incorporated in the FSS index, we use a panel-data setting similar to that in equation (3). However, we also consider the reverse causality, in which the FSS index has predictive power for financial cycle indicators, as in

$$
X_{i, t}=u_{i}+\beta F S S_{i, t-h}+e_{i, t} .
$$

The results for the lead-lag analysis are summarized in table 7 . Contemporaneously, the FSS index is significantly correlated, at least at the 5 percent confidence level, with the credit measures that characterize the financial cycle. In particular, as can be seen in column (1), an increase in the FSS index, which corresponds to a deterioration in sentiment, is accompanied by a contemporaneous increase in the credit-to-GDP gap and the debt service ratio. The significant relation between credit characteristics and the FSS index remains significant and in the same direction when the variables are lagged by one or four quarters (columns (4) and (5), respectively), which suggests that sentiment deteriorates following an increase in credit to GDP relative to its long-run trend or a deterioration in the debt service ratio. When the FSS index leads the indicator (columns (2) and (3)), the evidence suggests that a deterioration in FSS is followed by an improvement (decrease) in the credit-to-GDP ratio and the debt service ratio, although the effect is not significant at any standard confidence level.

The evidence for the asset valuation measures of the financial cycle suggests that a drop in asset prices is accompanied by an increase in the FSS index. In particular, a drop in bank stock prices relative to their market values, headline stock indexes relative to dividends paid, or a drop in property prices is accompanied by a deterioration in sentiment. Drops in asset prices are also followed by a significant deterioration of FSS indexes, and, conversely, 
a deterioration of FSS is followed by a further deterioration in asset prices.

The evidence for the systemic risk group of measures related to the financial cycle suggests that an increase in SRISK-to-GDP ratios or bank CDS spreads is accompanied by a significant deterioration of the FSS index. The lead-lag relation only remains significant for bank CDS spreads at the one-quarter horizon and suggests that an increase in CDS spreads is followed by a significant deterioration of the FSS index. Conversely, a deterioration of the FSS index is followed by a further increase in bank CDS spreads. Although the FSS index and stock return volatility are not significantly contemporaneously correlated, the evidence shows that an increase in the FSS index is followed by a significant increase in stock market volatility.

\subsubsection{Panel VAR}

The lead-lag patterns documented in table 7 suggest that financial cycle variables and financial sentiment might be endogenously determined. This finding is not surprising, as financial cycles are relatively long and central bank communications are unlikely to change drastically in the different phases of the cycle. We account for this potential endogeneity by estimating the following panel VAR:

$$
\mathbf{Y}_{i, t}=u_{i}+\Sigma_{l=1}^{L} \mathbf{Y}_{i, t-l} \mathbf{A}_{l}+e_{i, t}
$$

where $i$ and $t$ denote, respectively, the country and time dimension of the panel data. $\mathbf{Y}_{i, t}$ is a vector of dependent variables, which includes the FSS index and a financial cycle measure. $u_{i}$ is a vector of country fixed effects, and $e_{i, t}$ is a vector of idiosyncratic errors, with zero

mean and serially uncorrelated. $L$ is the number of lags in the VAR, which we assume is equal to 1 , given the relatively short length of our sample. The matrices $A_{l}$ are estimated using the GMM procedure in Abrigo and Love (2015).

Figure 4 shows the impulse response functions (IRFs) between the FSS index and each one of the alternative financial cycle characteristics for the panel VAR system in equation (4). To save space, we center the attention on the predictive power of the FSS index for 
financial cycle indicators. Overall, the results from the panel VAR confirm those from the lead-lag analysis and suggest that changes in the FSS index translate into changes in financial cycle indicators. In particular, shocks to the FSS index are followed by an increase in both the credit-to-GDP gap (panel (a)) and the debt service ratio (panel (b)), although the effect is significant only for the latter for up to two quarters. Shocks to the FSS index are also followed by a significant reduction in asset prices. In particular, shocks to the FSS index are followed by a significant reduction in bank stock prices relative to market values for up to four quarters (panel (c)). Although the effect of shocks to FSS on the headline stock index dividend yield is positive (panel (d)), this effect is not significant in a panel VAR setting, which would suggest a stronger link between financial stability and bank stock prices than other industries' stocks. Shocks to the FSS index are also followed by a significant reduction of real property prices for up to four quarters (panel (e)). Finally, shocks to the FSS index are followed by a significant deterioration of the systemic risk characteristics of the financial cycle - an increase in the SRISK-to-GDP ratio, bank CDS spreads (only significant up to two quarters ahead), and stock market volatility (panels (f) to (g), respectively).

We perform a set of robustness tests on our benchmark panel VAR results in figure 4 . First, we explore the robustness of our results to adding the VIX as a third variable in the panel VAR vector of dependent variables, $\mathbf{Y}_{i, t}$ in equation (4). ${ }^{9}$ Second, we explore the robustness of our results to two alternative methods to calculate the FSS index. In the first alternative method, we use the dictionary in LM, instead of our financial stability dictionary, to calculate each country's FSS index. In the second method, we use indexes standardized at the country level, which essentially controls for country-level fixed effects that can be due, among other things, to idiosyncratic uses of language. Third, we assess the robustness of our results to using a longer sample starting in 2002 with a reduced sample of countries with FSRs available from that year. Some results for the robustness tests are left unreported, to

\footnotetext{
${ }^{9}$ The VIX is the option-implied volatility of the S\&P 500 index. The methodology to calculate the VIX was proposed by Carr and Madan (1998) and Britten-Jones and Neuberger (2000). Time series for the VIX are obtained from Bloomberg.
} 
save space. ${ }^{10}$

Figure 5 shows the IRFs when we add the VIX as a control variable. The results show that, overall, our benchmark panel VAR results are robust to controlling for risk aversion in the vector of endogenous variables (see Bekaert et al., 2014). ${ }^{11}$ There are, however, some differences with our benchmark results. In particular, the effect of shocks to the FSS index becomes insignificant for bank CDS spreads, and the IRF pattern changes for stock return volatility, with the effect of shocks to the FSS index significant only for horizons longer than two months.

Figure 6 shows the IRFs when we replace our FSS index with an index calculated using the dictionary in LM. Although our benchmark panel VAR results for the informational content of the FSS index remain robust, responses to shocks to the FSS index calculated with the LM dictionary are closer to zero for all variables considered. The similarity between the results using the benchmark FSS index and those with the index calculated using LM's dictionary is not surprising, as these two dictionaries share almost 70 percent of their words (see table 2).

In unreported results, we show that our benchmark results remain unchanged when we use FSS indexes standardized at the country level. In unreported results, we also show that, when we use a longer sample including fewer countries with reports available from 2002, our benchmark results remain virtually unchanged.

We also explore two extensions of our FSS index. The first extension is the negativity index, $F S S^{-}$, which is calculated using only negative words in the numerator of the FSS index; that is,

$$
F S S_{\text {country,period }}^{-}=\frac{\# \text { Negative words }}{\# \text { Total words }}
$$

The IRFs for this index are shown in figure 7. There are interesting differences between

\footnotetext{
${ }^{10}$ These results are available, upon request, from the authors.

${ }^{11}$ The IRF for a bivariate VAR with the FSS index and VIX resembles that for stock market volatility (see panel (h) of figure 4). That is, a shock to the FSS index is followed by a significant increase in the VIX.
} 
the patterns of IRFs for the negativity index and those for the FSS index. In particular, a shock to $F S S^{-}$is followed by a borderline significant increase in the credit-to-GDP gap at the one-month horizon, while the effect is not significant for the FSS index. In contrast, a shock to $F S S^{-}$is not followed by a significant decrease in market-to-book ratios or by a significant deterioration in bank CDS spreads.

The second extension is an excitement index, $F S S^{*}$, which is calculated as

$$
F S S_{\text {country,period }}^{*}=\frac{\# \text { Negative words }{ }^{2}+\# \text { Positive words }}{2}
$$

The IRFs for this index are shown in figure 8. The patterns of IRFs for the excitement index are very similar to those for the negativity index. Specifically, in contrast to the results

for the FSS index, the effect on market-to-book ratios and bank CDS spreads becomes insignificant. Interestingly, however, an increase in the excitement index is followed by a significant increase in credit-to-GDP ratios for all horizons considered, in contrast to the insignificant effect documented for the benchmark FSS index.

In sum, our results for the panel VAR suggest that central banks not only incorporate the information from financial cycle indicator but are also able to foresee the dynamics of these indicators, as captured by the FSS index. In particular, an increase in FSS indexes, which can be interpreted as a deterioration in sentiment, is followed by a significant deterioration of most financial cycle indicators.

\subsubsection{Financial stability sentiment and banking crises}

In the previous section, we showed that central banks are able to assess the future path of indicators that characterize the financial cycle. However, financial stability monitoring and more aggressive communication about financial stability concerns are more likely to be clustered around turning points in the financial cycle, such as at the starting point of banking crises. We investigate further the relation between financial sentiment and the financial cycle by assessing whether the sentiment conveyed by central banks in FSRs deteriorates before a 
banking crisis. We test that hypothesis by estimating the following probit model:

$$
C_{i, t}=u_{i}+\beta_{F S S} F S S_{i, t-h}+\mathbf{X}_{i, t-h}+e_{i, t}
$$

where $C_{i, t}$ is a dummy variable that takes on the value of 1 when a banking crisis occurs in country $i$ at time $t$ and 0 otherwise. The banking crisis dummies are obtained from Laeven and Valencia (2013). X contains two variables commonly used in the literature as predictors of banking crises: the credit-to-GDP gap and the debt service ratio for private nonfinancial corporations (see Drehmann et al., 2015; and Borio, 2014).

The results for the probit model are summarized in table 8. Panel (a) presents the results for univariate regressions that only include the FSS index, and panel (b) reports the estimates for multivariate regressions that add the credit-to-GDP gap and debt service ratio as regressors. Our results suggest that the FSS index is a useful predictor of one-quarterahead banking crises, irrespective of whether we control for the credit-to-GDP gap and the debt service ratio. The coefficient associated with the one-quarter lagged FSS index is significant at the 10 percent level. The estimated coefficient is also economically significanta 1 percentage point increase in the FSS index, which corresponds to 1.25 times the average standard deviation of FSS indexes, is followed by an 18.21 (22.04) percent probability of a banking crisis for the univariate (multivariate) setting. Similarly, the area under the curve (AUC), a measure of fit, is well above $0.50-0.64$ and 0.70 for the univariate and multivariate setting, respectively. More importantly, the predictive power of the FSS index for banking crises is additional to that of the credit-to-GDP gap or the debt service ratio. Interestingly, although the AUC for these two variables is above 0.50, the coefficient associated with them is not statistically significant.

Although central banks appear to be able to predict banking crises, or at least intensify their communications around these episodes, the predictive power of the FSS index is only borderline significant. Our results could be weakened for two reasons. On the one hand, the sample period used for the estimations is limited. In most cases, the only crisis captured in 
this time period is the GFC. The lack of crisis episodes may reduce the power of our test. On the other hand, central banks may ramp up their negative sentiment around these episodes, but not substantially compared to normal times. Central banks could be either more cautious about the outlook or could decide to focus on communicating the resilience of the financial sector instead of the risks identified, which would have a contradictory effect on the FSS index. Nonetheless, for the episodes covered, we find that the FSS index does better at predicting banking crises than the alternative early-warning measures used in the literature. This result shows that, at least in relative terms, the central banks' communication is a more useful predictor of crises than these other commonly used indicators.

\section{Conclusion}

Text analysis techniques have been used extensively to analyze central banks' communications on monetary policy. However, although financial stability has gained prominence beyond monetary policy after the global financial crisis and the European sovereign debt crisis, communications on this topic have garnered less attention in the literature.

We propose a dictionary tailored specifically to the financial stability context, as we find that a large portion of words in FSRs, one of central banks communication tools on financial stability, convey a different connotation compared to that assigned in previous general or finance-specific dictionaries. We use this dictionary to construct the FSS index, which summarizes the sentiment in financial stability communications.

We show that our index is useful for financial stability analysis. In particular, we find that a set of indicators commonly used in the literature on early-warning systems explains the time variation in the FSS index, with concerns about the banking sector being the main driver of the index's dynamics. We also show that the FSS index is contemporaneously correlated with indicators of the financial cycle. These findings imply that central banks incorporate developments in the financial cycle in their financial stability communications. In addition, using a panel VAR that controls for endogeneity between the FSS index and 
financial cycle indicators, we find that the FSS index has predictive power for most financial cycle indicators. In particular, an increase in the FSS index, which signals a deterioration in sentiment, is followed by a further deterioration of financial cycle indicators. We interpret these results as preliminary evidence that, although central banks are able to identify and communicate financial stability risks, communications through FSRs alone are not sufficient to alleviate a deterioration in financial vulnerabilities. Finally, we analyze whether central banks are able to predict and communicate turning points in the financial cycle. Using a probit model, we show that the FSS index is a useful predictor of banking crises, even after controlling for commonly used predictors of these events. This finding is evidence that central banks change the sentiment in their communications prior to crises, although they are not able to prevent them.

An important caveat in our analysis is that our estimation strategy does not take into account the specific financial stability governance framework in each country. For example, we do not take into account whether or not central banks have a direct supervisory role or regulatory powers. Different governance frameworks may lead central banks to be more aggressive (or passive) in communicating financial stability developments. In future research, we plan to study the interaction between communication strategies and central banks' financial stability tools.

\section{References}

Abrigo, M., Love, I., 2015. Estimation of panel VAR in Stata: A package of programs Unpublished working paper. University of Hawaii.

Bekaert, G., Ehrmann, M., Fratzscher, M., Mehl, A., 2014. The global crisis and equity market contagion. Journal of Finance 69, 2597-2649.

Blinder, A. S., Ehrmann, M., Fratzscher, M., Haan, J. D., Jansen, D.-J., 2008. Central bank communication and monetary policy: A survey of theory and evidence. Journal of Economic Literature 46, 910-45. 
Borio, C., 2014. The financial cycle and macroeconomics: What have we learnt? Journal of Banking and Finance 45, 182-198.

Born, B., Ehrmann, M., Fratzscher, M., 2014. Central bank communication on financial stability. Economic Journal 124, 701-734.

Britten-Jones, M., Neuberger, A., 2000. Option prices, implied price processes, and stochastic volatility. Journal of Finance 55, 839-866.

Brownlees, C. T., Engle, R. F., 2016. SRISK: A conditional capital shortfall measure of systemic risk. The Review of Financial Studies (forthcoming).

Carr, P., Madan, D., 1998. Towards a theory of volatility trading. In: Jarrow, R. (ed.), Volatility: New Estimation Techniques for Pricing Derivatives, Risk Books, London.

Cihak, M., 2006. How do central banks write on financial stability? Unpublished working paper. International Monetary Fund.

Cihak, M., Muoz, S., Ten Sharifuddin, S., Tintchev, K., 2012. Financial stability reports: What are they good for? Unpublished working paper. International Monetary Fund.

Drehmann, M., Illes, A., Juseliusm, M., Santos, M., 2015. How much income is used for debt payments? A new database for debt service ratios. BIS Quarterly Review, September .

Ericsson, N., 2016. Eliciting GDP forecasts from the FOMC's minutes around the financial crisis. International Journal of Forecasting 32, 571-583.

Hansen, S., McMahon, M., 2016. Shocking language: Understanding the macroeconomic effects of central bank communication. Journal of International Economics 99, Supplement 1, S114 - S133, 38th Annual NBER International Seminar on Macroeconomics.

Hatzius, J., Hooper, P., Mishkin, F., Schoenholtz, K., Watson, M., 2010. Financial condition index: A fresh look after the financial crisis Unpublished working paper. NBER.

Henry, E., 2006. Market reaction to verbal components of earnings press releases: Event study using a predictive algorithm. Journal of Emerging Technologies in Accounting 3, $1-19$.

Henry, E., 2008. Are investors influenced by how earnings press releases are written? The Journal of Business Communication 45, 363-407. 
Henry, E., Leone, A. J., 2016. Measuring qualitative information in capital markets research: Comparison of alternative methodologies to measure disclosure tone. Accounting Review 91, 153-178.

Hubert, P., Labondance, F., 2017. Central bank sentiment and policy expectations Unpublished working paper. Bank of England.

International Monetary Fund, 2010. The IMF-FSB early warning exercise. Design and Methodological Toolkit. September.

Jeanneau, S., 2014. Financial stability objectives and arrangements-What is new? BIS papers No. 76.

Jegadeesh, N., Wu, D., 2013. Word power: A new approach for content analysis. Journal of Financial Economics 110, $712-729$.

Kearney, C., Liu, S., 2014. Textual sentiment in finance: A survey of methods and models. International Review of Financial Analysis 33, 171-185.

Laeven, L., Valencia, F., 2013. Systemic banking crises database. IMF Economic Review 61, $225-270$.

Li, F., 2010. The information content of forward-looking statements in corporate filings: A naive Bayesian machine learning algorithm approach. Journal of Accounting Research 48, 1049-1102.

Loughran, T., McDonald, B., 2011. When is a liability not a liability? Textual analysis, dictionaries, and 10-Ks. Journal of Finance 66, 35-65.

Loughran, T., McDonald, B., 2016. The use of word lists in textual analysis. Journal of Behavioral Finance 16, 1-11.

Ng, T., 2011. The predictive content of financial cycle measures for output fluctuations. BIS Quarterly Review .

Osterloo, S., de Haan, J., Jong-A-Pin, R., 2011. Financial stability reviews: A first empirical analysis. Journal of Financial Stability 2, 337-355.

Stekler, H. O., Symington, H., 2016. Evaluating qualitative forecasts: The FOMC minutes, 20062010. International Journal of Forecasting 32, 559-570.

Wooldridge, J., 2002. Econometric Analysis of Cross Section and Panel Data. MIT press. 


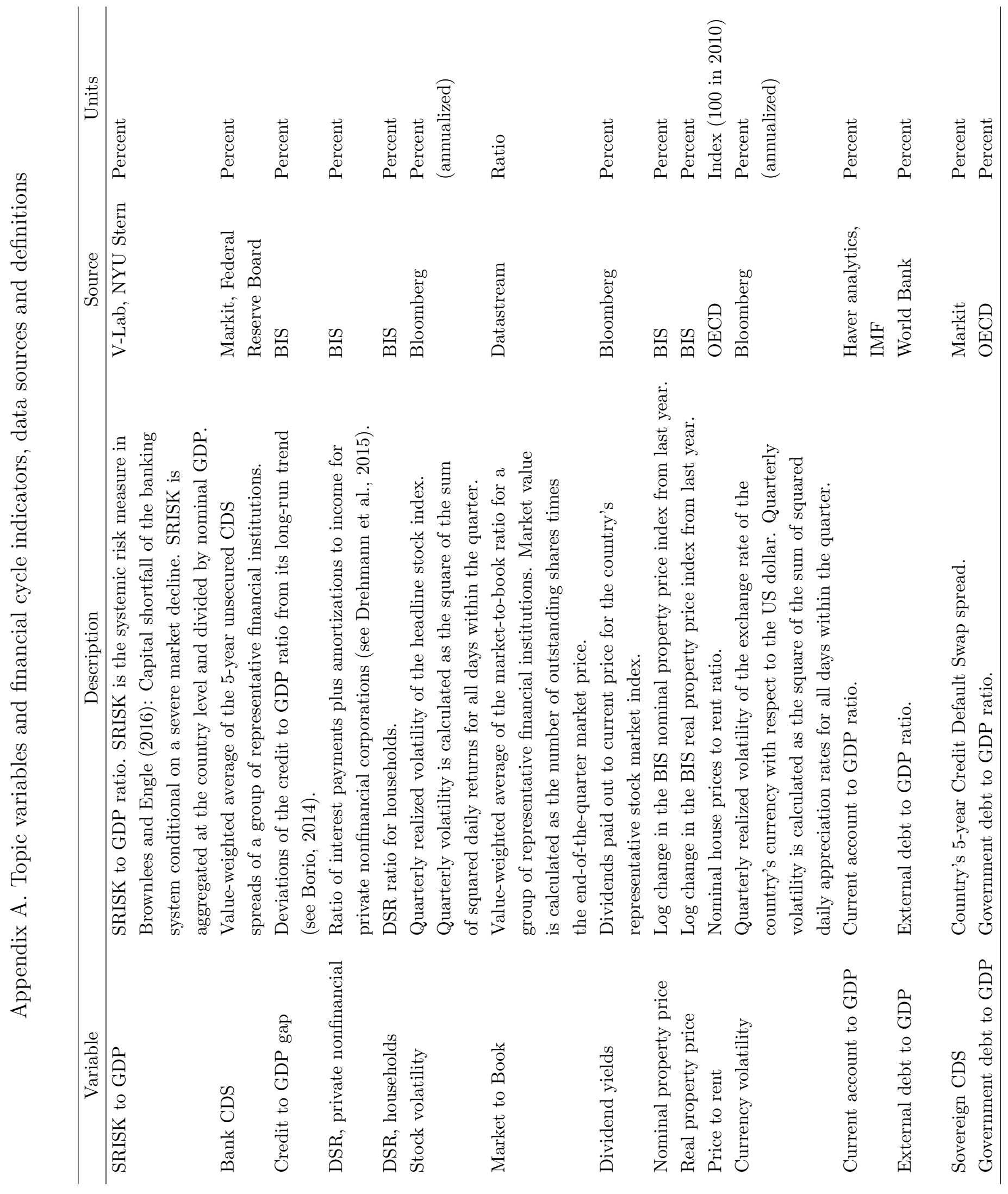


Table 1: Financial stability reports, availability

This table summarizes the availability of FSRs written in or translated into English. Frequency denotes the number of times in a year an FSR is released, on average. Occasionally, central banks release reports with a different frequency in a given year, and there are missing reports for particular countries for certain years. We account for these differences in our empirical exercise in section 4. The euro-area report aggregates information for all euro-area countries, while the IMF report aggregates global information.

\begin{tabular}{|c|c|c|c|}
\hline Publisher & Institution & Availability & Frequency \\
\hline Argentina & Central Bank of Argentina & $2004-2015$ & 2 \\
\hline Australia & Reserve Bank of Australia & $2004-2016$ & 2 \\
\hline Austria & Oesterreichische Nationalbank & $2001-2016$ & 2 \\
\hline Bangladesh & Bangladesh Bank & 2011-2015 & 1 \\
\hline Belgium & National Bank of Belgium & $2002-2016$ & 1 \\
\hline Brazil & Banco Central do Brasil & $2002-2010$ & 2 \\
\hline Canada & Bank of Canada & $2002-2016$ & 2 \\
\hline Chile & Banco Central de Chile & 2004-2016 & 2 \\
\hline China & People's Bank of China & 2011-2015 & 1 \\
\hline Colombia & Banco de la Republica Colombia & $2005-2014$ & 2 \\
\hline Croatia & Croatian National Bank & 2008-2016 & 2 \\
\hline Cyprus & Central Bank of Cyprus & 2015 & 1 \\
\hline Czech Rep. & Czech National Bank & $2004-2016$ & 1 \\
\hline Denmark & Danmarks Nationalbank & $2002-2016$ & 1 \\
\hline Estonia & Bank of Estonia & $2003-2016$ & 2 \\
\hline Germany & Deutsche Bundesbank & $2004-2015$ & 1 \\
\hline Greece & Bank of Greece & $2009-2010$ & 1 \\
\hline Hong Kong & Hong Kong Monetary Authority & $2003-2016$ & 2 \\
\hline Hungary & Magyar Nemzeti Bank & $2000-2016$ & 2 \\
\hline Iceland & Sedlabanki Islands & $2005-2015$ & 1 \\
\hline India & Reserve Bank of India & $2010-2016$ & 2 \\
\hline Indonesia & Bank Indonesia & $2003-2015$ & 2 \\
\hline Ireland & Central Bank of Ireland & $2012-2016$ & 2 \\
\hline Israel & Bank of Israel & $2014-2015$ & 2 \\
\hline Italy & Banca d'Italia & $2010-2016$ & 1 \\
\hline Jamaica & Bank of Jamaica & $2006-2015$ & 1 \\
\hline Japan & Bank of Japan & $2006-2016$ & 2 \\
\hline Korea & Bank of Korea & $2005-2015$ & 2 \\
\hline Kyrgyzstan & National Bank of Kyrgyz Rep. & $2005-2015$ & 2 \\
\hline Latvia & Latvijas Banka & $2003-2015$ & 1 \\
\hline
\end{tabular}


Table 1: Financial stability reports, availability, continued

\begin{tabular}{llrr}
\hline \multicolumn{1}{c}{ Publisher } & \multicolumn{1}{c}{ Institution } & Availability & Frequency \\
\hline Lithuania & Bank of Lithuania & $2007-2016$ & 1 \\
Macedonia & National Bank of Macedonia & $2007-2015$ & 1 \\
Malawi & Reserve Bank of Malawi & $2012-2016$ & 2 \\
Malaysia & Bank Negara Malaysia & $2007-2016$ & 1 \\
Malta & Central Bank of Malta & $2009-2015$ & 1 \\
Namibia & Bank of Namibia & $2008-2016$ & 2 \\
Nepal & Nepal Rastra Bank & $2012-2016$ & 2 \\
Netherlands & De Nederlandsche Bank & $2004-2016$ & 2 \\
New Zealand & Reserve Bank of New Zealand & $2004-2016$ & 2 \\
Nigeria & Central Bank of Nigeria & $2010-2015$ & 2 \\
Norway & Norges Bank & $2000-2015$ & 1 \\
Poland & National Bank of Poland & $2003-2016$ & 2 \\
Portugal & Banco de Portugal & $2005-2015$ & 2 \\
Romania & National Bank of Romania & $2006-2015$ & 1 \\
Russia & Bank of Russia & $2012-2016$ & 2 \\
Saudi Arabia & Saudi Arabian Monetary Agency & 2015 & 1 \\
Singapore & Monetary Authority of Singapore & $2004-2015$ & 1 \\
Slovakia & Narodna Banka Slovenska & $2005-2016$ & 2 \\
Slovenia & Banka Slovenije & $2004-2015$ & 1 \\
South Africa & South African Reserve Bank & $2004-2016$ & 2 \\
Spain & Banco de Espana & $2002-2016$ & 2 \\
Sri Lanka & Central Bank of Sri Lanka & $2009-2013$ & 1 \\
Suriname & Centrale Bank Van Suriname & 2016 & 1 \\
Sweden & Sveriges Riksbank & $2000-2016$ & 2 \\
Switzerland & Schweizerische Nationalbank & $2003-2016$ & 1 \\
Taiwan & Central Bank of Taiwan & $2008-2015$ & 1 \\
Thailand & Bank of Thailand & $2013-2015$ & 1 \\
Trinidad & Central Bank of Trinidad & $2009-2015$ & 2 \\
Turkey & Merkez Bankasi & $2005-2016$ & 2 \\
U.A.E & Central Bank of the U.A.E & $2012-2015$ & 1 \\
Uganda & Bank of Uganda & $2010-2015$ & 1 \\
United Kingdom & Bank of England & $2000-2016$ & 2 \\
USA & Financial Stability Oversight Council & $2011-2016$ & 1 \\
IMF & IMF & $2002-16$ & 2 \\
Euro area & European Central Bank & $2004-2016$ & 2 \\
\hline & & &
\end{tabular}


Table 2: Financial stability dictionary, word distribution and frequency

This table shows the distribution of positive and negative words in our financial stability dictionary introduced in section 2. The word distribution shows the number of dictionary words as a percentage of all distinct words (after removing stop words) across all FSRs used in our sample (see table 1). The word frequency is the number of times words occur across all FSRs divided by the sum of all words across all FSRs. We also report a comparison between the words in our dictionary and the dictionary in LM. Uniquely financial stability words refers to words not classified in LM's dictionary.

\begin{tabular}{lccc}
\hline & $\begin{array}{c}\text { Number of } \\
\text { words }\end{array}$ & $\begin{array}{c}\text { Word distribution } \\
\text { (percent) }\end{array}$ & $\begin{array}{c}\text { Word frequency } \\
\text { (percent) }\end{array}$ \\
\hline Total financial stability & 391 & 5.38 & 4.01 \\
Positive words & 96 & 1.32 & 1.45 \\
Negative words & 295 & 4.06 & 2.56 \\
\hline Overlap with LM & 270 & 3.72 & 3.28 \\
Uniquely financial stability words & 121 & 1.67 & 0.73 \\
\hline
\end{tabular}


Table 3: FSS index, summary statistics

This table shows a set of summary statistics for the FSS indexes for the 35 countries with FSRs available at least once a year between 2005 and 2015. We also show summary statistics for the euro area and the IMF FSS indexes. The minimum and maximum date are the dates when the FSS index takes on its lowest and highest values, respectively. $\mathrm{N}$ is the total number of reports between January 2005 and December 2015. Standard deviation is abbreviated as SD.

\begin{tabular}{lrrrrrrr}
\hline & $\mathrm{N}$ & Mean & SD & Kurtosis & Skewness & Min. date & Max. date \\
\hline Argentina & 22 & -0.49 & 0.77 & 2.27 & 0.03 & Apr 05 & Apr 09 \\
Australia & 22 & 1.14 & 0.64 & 2.88 & 0.72 & Mar 06 & Sep 08 \\
Austria & 22 & 0.83 & 0.72 & 2.62 & 0.45 & Jun 14 & Dec 08 \\
Belgium & 11 & 0.97 & 0.67 & 2.05 & 0.32 & Jun 05 & Jun 09 \\
Canada & 22 & 2.53 & 0.86 & 2.97 & -0.72 & Jun 06 & Dec 08 \\
Chile & 22 & 0.82 & 0.76 & 3.21 & -0.21 & Jun 05 & Dec 07 \\
Colombia & 16 & 0.17 & 0.63 & 3.72 & 0.17 & Jul 05 & Mar 09 \\
Czech Republic & 10 & 1.38 & 0.70 & 2.05 & 0.16 & May 06 & May 09 \\
Denmark & 15 & 1.39 & 1.30 & 3.60 & 1.19 & Dec 13 & Dec 08 \\
Estonia & 22 & 0.47 & 0.64 & 2.07 & -0.13 & Nov 05 & Oct 11 \\
Germany & 10 & 1.55 & 0.47 & 1.72 & -0.31 & Nov 05 & Nov 07 \\
Hong Kong & 21 & 0.65 & 0.89 & 2.10 & 0.36 & Mar 11 & Dec 08 \\
Hungary & 20 & 1.36 & 0.86 & 1.56 & 0.09 & Apr 05 & Apr 09 \\
Iceland & 16 & 0.85 & 0.53 & 2.28 & -0.14 & Oct 15 & Oct 09 \\
Indonesia & 21 & 0.18 & 0.81 & 3.24 & -0.11 & Sep 10 & Mar 09 \\
Japan & 18 & 1.25 & 0.80 & 2.92 & 0.75 & Sep 07 & Mar 09 \\
Latvia & 13 & 0.72 & 0.84 & 4.01 & 1.10 & Jan 06 & Jan 09 \\
Lithuania & 9 & 1.31 & 0.66 & 2.49 & -0.73 & May 07 & May 12 \\
Malaysia & 9 & -0.58 & 0.66 & 5.46 & 1.89 & Mar 13 & Mar 09 \\
Netherlands & 21 & 2.19 & 0.87 & 2.39 & 0.14 & Nov 10 & May 09 \\
New Zealand & 22 & 1.28 & 0.78 & 3.12 & 0.58 & May 10 & Nov 08 \\
Norway & 19 & 1.38 & 0.97 & 1.78 & -0.13 & May 05 & May 09 \\
Poland & 20 & 0.87 & 0.63 & 2.02 & 0.03 & Jun 05 & Jun 09 \\
\hline & & & & & & & \\
\hline
\end{tabular}


Table 3: FSS index, summary statistics, continued

\begin{tabular}{lrrrrrrr}
\hline & N & Mean & SD & Kurtosis & Skewness & Min. date & Max. date \\
\hline Portugal & 17 & 0.89 & 0.74 & 2.79 & 0.86 & May 15 & May 09 \\
Romania & 10 & 0.96 & 0.54 & 1.95 & 0.58 & Sep 14 & May 09 \\
Singapore & 13 & 1.12 & 1.21 & 2.61 & 0.69 & Jun 06 & Dec 08 \\
Slovakia & 18 & 1.14 & 0.66 & 2.14 & -0.10 & May 05 & May 09 \\
Slovenia & 9 & 0.97 & 0.79 & 1.45 & -0.37 & May 06 & May 12 \\
South Africa & 22 & 2.15 & 0.71 & 5.37 & 1.49 & Mar 07 & Mar 09 \\
South Korea & 22 & 1.53 & 1.11 & 2.68 & 0.36 & Apr 10 & Apr 09 \\
Spain & 22 & 0.66 & 1.09 & 2.30 & 0.08 & May 06 & Nov 11 \\
Sweden & 22 & 1.64 & 0.76 & 2.91 & 0.94 & Nov 13 & Nov 08 \\
Switzerland & 11 & 1.31 & 1.18 & 2.24 & 0.38 & Jun 06 & Jun 09 \\
Turkey & 21 & 0.53 & 0.59 & 2.52 & 0.36 & Jun 06 & Nov 11 \\
United Kingdom & 21 & 2.10 & 0.78 & 2.03 & 0.36 & Jun 14 & Oct 07 \\
Euro area & 22 & 1.95 & 0.85 & 2.77 & 0.90 & Dec 05 & Dec 08 \\
IMF & 22 & 2.56 & 0.94 & 2.41 & -0.20 & Apr 05 & Sep 11 \\
\hline
\end{tabular}


Table 4: Words defining topics

This table shows the words used to identify sentences that refer to a particular topic. These words are used to calculate the topic indexes introduced in section 4.1. We only report the singular form of each word, although, to calculate the topic indexes, we also use their plural forms. We identify words that relate to real estate separately from words that relate to the rest of the household sector.

\begin{tabular}{ll}
\hline Topic & Words associated \\
\hline Banking & $\begin{array}{l}\text { Bank, financial/depository institution, financial service, lending standard } \\
\text { interbank, nonperforming loan/exposure (NPL and NPE) }\end{array}$ \\
Valuation & $\begin{array}{l}\text { Financial/capital/commodity market, equity/bond/stock return, derivative, } \\
\text { risky/riskier/financial asset, bond yield, debt spread, corporate bond }\end{array}$ \\
Household & $\begin{array}{l}\text { Credit card, personal/private/auto/vehicle loan, private consumption, } \\
\text { consumer credit, auto/vehicle debt }\end{array}$ \\
Real estate & $\begin{array}{l}\text { Real estate, residential, property/house price, housing, property market } \\
\text { home purchase, mortgage }\end{array}$ \\
Corporate & $\begin{array}{l}\text { Firm, SME, nonfinancial company/business/private/corporation, } \\
\text { corporate sector }\end{array}$ \\
External & $\begin{array}{l}\text { Current account, reserves, external debt/imbalance, balance of payments, } \\
\text { foreign currency, exports, imports, emerging markets, international, }\end{array}$ \\
& EME, advanced economies, global, foreign, \\
Government debt, fiscal, fiscal debt/balance
\end{tabular}




\section{Table 5: Topics driving financial stability sentiment}

This table shows the estimates of the coefficients associated with the topic indexes in the following panel-data regression:

$$
F S S_{i, t}=u_{i}+\sum_{j=1}^{S} B_{j} F S S_{i, t}^{j}+\sum_{j=1}^{S} C_{j} F r e q_{i, t}^{j}+e_{i, t},
$$

where $F S S_{i}$ represents each country's FSS index, $F S S_{i}^{j}$ is the FSS index for topic $j$ for country $i$ (see table 4 and section 4.1), and Freq ${ }_{i}^{j}$ is the frequency at which topic $j$ words are used in each report. Sentiment indexes are standardized to facilitate sorting the coefficients according to their relevance at explaining the time variation in the overall FSS index. The coefficients associated with the frequency of topic words are omitted to save space. Standard errors are corrected using Huber-White standard deviations (see Wooldridge, 2002), and are reported in parentheses. ${ }^{*},{ }^{* *}$, and ${ }^{* * *}$ represent the usual $10 \%, 5 \%$, and $1 \%$ significance levels.

\begin{tabular}{lr}
\hline Topic & \\
\hline Banking & $0.48^{* * *}$ \\
& $(0.04)$ \\
Household & $0.19^{* * *}$ \\
& $(0.02)$ \\
Valuation & $0.18^{* * *}$ \\
& $(0.02)$ \\
Corporate & $0.15^{* * *}$ \\
& $(0.03)$ \\
External & $0.13^{* * *}$ \\
& $(0.02)$ \\
Real estate & $0.08^{* *}$ \\
& $(0.02)$ \\
Sovereign & 0.03 \\
& $(0.02)$ \\
\hline
\end{tabular}




\section{Table 6: Information in topic indexes}

This table summarizes the results for the information incorporated in topic subindexes. The table shows the estimated coefficients for the following panel-data regression setting:

$$
F S S_{i, t}^{j}=u_{i}+\beta X_{i, t-h}^{j}+e_{i, t},
$$

where $F S S_{i}^{j}$ represents the FSS index for topic $j$ for country $i$ (see table 4), and $X_{i, t-h}^{j}$ is each one of the $h$-quarter lagged topic-specific variables defined in appendix A. Some of these measures fall into multiple topic categories. We report the results for $h=0$ (contemporaneous), $h=1$, and $h=4$. Standard errors are corrected using Huber-White standard deviations (see Wooldridge, 2002), and are reported in parentheses. ${ }^{*}, * *$, and ${ }^{* * *}$ represent the usual $10 \%, 5 \%$, and $1 \%$ significance levels. For each combination of subindex and topic-specific variables, we also report the total number of quarterly observations, $\mathrm{N}$.

\begin{tabular}{llcccc}
\hline Subindex & Variable & $h=0$ & $h=1$ & $h=4$ & $\mathrm{~N}$ \\
\hline Bank & SRISK to GDP & $0.12^{* * *}$ & $0.03^{* *}$ & 0.01 & 1,297 \\
& & $(0.03)$ & $(0.01)$ & $(0.03)$ & \\
& Bank CDS & $0.28^{* *}$ & $0.08^{*}$ & 0.02 & 848 \\
& & $(0.08)$ & $(0.04)$ & $(0.05)$ & \\
& Credit to GDP gap & $0.02^{*}$ & $0.00^{*}$ & 0.01 & 1,170 \\
& & $(0.01)$ & 0.00 & $(0.01)$ & \\
& DSR, private nonfinancial & $0.19^{* * *}$ & $0.05^{* *}$ & 0.09 & 950 \\
& $(0.04)$ & $(0.02)$ & $(0.05)$ & \\
\hline
\end{tabular}


Table 6: Information in topic indexes, continued

\begin{tabular}{|c|c|c|c|c|c|}
\hline Subindex & Variable & $h=0$ & $h=1$ & $h=4$ & $\mathrm{~N}$ \\
\hline \multirow[t]{2}{*}{ Household } & DSR, households & $0.50^{* * *}$ & $0.20^{* * *}$ & $0.56^{* *}$ & 564 \\
\hline & & $(0.08)$ & $(0.04)$ & $(0.13)$ & \\
\hline \multirow[t]{6}{*}{ Valuation } & Stock volatility & 0.00 & $0.01^{* * *}$ & $0.00^{* * *}$ & 1,363 \\
\hline & & $(0.01)$ & $(0.00)$ & $(0.00)$ & \\
\hline & Market to book & $-0.92^{* * *}$ & $-0.18^{*}$ & $0.52^{* *}$ & 1,208 \\
\hline & & $(0.17)$ & $(0.07)$ & $(0.16)$ & \\
\hline & Dividend yield & $0.66^{* * *}$ & $0.21^{* * *}$ & -0.25 & 1,066 \\
\hline & & $(0.09)$ & $(0.04)$ & $(0.14)$ & \\
\hline \multirow[t]{2}{*}{ Corporate } & DSR, private nonfinancial & $0.34^{* * *}$ & $0.16^{* * *}$ & $0.37^{* * *}$ & 950 \\
\hline & & $(0.07)$ & $(0.03)$ & $(0.09)$ & \\
\hline \multirow[t]{6}{*}{ External } & Currency volatility & $0.00^{* *}$ & $0.00^{*}$ & 0.00 & 1,419 \\
\hline & & $(0.00)$ & $(0.00)$ & $(0.00)$ & \\
\hline & Current account to GDP & -0.06 & -0.01 & -0.05 & 819 \\
\hline & & $(0.03)$ & $(0.02)$ & $(0.05)$ & \\
\hline & External debt to GDP & 0.00 & 0.00 & 0.00 & 548 \\
\hline & & $(0.00)$ & $(0.00)$ & $(0.00)$ & \\
\hline \multirow[t]{6}{*}{ Real estate } & Nominal property prices & $-0.04^{* * *}$ & 0.00 & 0.01 & 1,230 \\
\hline & & $(0.01)$ & $(0.00)$ & $(0.01)$ & \\
\hline & Real Property prices & $-0.04^{* * *}$ & 0.00 & 0.01 & 1,230 \\
\hline & & $(0.01)$ & $(0.00)$ & $(0.01)$ & \\
\hline & Price to rent & 0.01 & $0.01^{*}$ & $0.03^{*}$ & 655 \\
\hline & & $(0.01)$ & $(0.00)$ & $(0.01)$ & \\
\hline \multirow[t]{4}{*}{ Sovereign } & Sovereign CDS & $0.22^{*}$ & $0.09^{*}$ & 0.06 & 1,351 \\
\hline & & $(0.09)$ & $(0.04)$ & $(0.06)$ & \\
\hline & Government debt to GDP & $0.03^{* *}$ & 0.00 & 0.01 & 1,413 \\
\hline & & $(0.01)$ & $(0.00)$ & $(0.01)$ & \\
\hline
\end{tabular}


Table 7: Contemporaneous and lead-lag relations between financial cycle indicators and the FSS index

This table summarizes the results for the contemporaneous and lead-lag relations between each of the financial cycle indicators and the FSS index. Specifically, columns (1) to (3) show the estimate of the coefficient associated with the FSS index in the following panel-data regressions:

$$
X_{i, t}=u_{i}+\beta F S S_{i, t-h}+\gamma X_{i, t-h}+e_{i, t},
$$

for $h=0, h=1$, and $h=4$, respectively. $F S S_{i}$ represents each country's FSS index and $X_{i}$ is each of the financial cycle indicators considered. We classify these indicators into three categories. The first category, credit indicators, includes the credit-to-GDP gap and debt service ratios (DSRs) for private nonfinancial corporations. The second category, valuation indicators, includes the market-to-book ratio for banks, the dividend yield for each country's representative stock index, and log changes in real property prices with respect to one year ago. The third category, systemic risk indicators, includes the SRISK-to-GDP ratio, the average CDS spread for banks, and the volatility of the representative stock market index. Appendix A provides a detailed description of these financial cycle characteristics as well as their sources. Standard errors are reported in parentheses and are corrected using Huber-White standard deviations (see Wooldridge, $2002) .{ }^{* * *}$, and ${ }^{* * *}$ represent the usual 10\%, 5\%, and 1\% significance levels. Columns (4) and (5) show the coefficient associated with each of the financial cycle indicators in the following regressions:

$$
F S S_{i, t}=u_{i}+\gamma X_{i, t-1}+\beta F S S_{i, t-h}+e_{i, t},
$$

for $h=1$ and $h=4$, respectively. For each variable, we also report the total number of quarterly observations,

\begin{tabular}{|c|c|c|c|c|c|c|}
\hline & $(1)$ & $(2)$ & $(3)$ & $(4)$ & $(5)$ & \multirow[b]{3}{*}{$\mathrm{N}$} \\
\hline & \multirow[b]{2}{*}{$h=0$} & \multicolumn{2}{|c|}{ Lagged FSS } & \multicolumn{2}{|c|}{ Lagged $X$} & \\
\hline & & $h=1$ & $h=4$ & $h=1$ & $h=4$ & \\
\hline \multicolumn{7}{|l|}{ Credit } \\
\hline \multirow[t]{2}{*}{ Credit to GDP gap } & $0.02^{* *}$ & -0.03 & -0.56 & $0.00^{* *}$ & $0.01^{* *}$ & 1,170 \\
\hline & $(0.01)$ & $(0.16)$ & $(0.53)$ & $(0.00)$ & $(0.00)$ & \\
\hline \multirow[t]{2}{*}{ DSR, private nonfinancial } & $0.21^{* * *}$ & -0.03 & -0.18 & $0.06^{* * *}$ & $0.13^{* *}$ & 950 \\
\hline & $(0.03)$ & $(0.05)$ & $(0.15)$ & $(0.01)$ & $(0.04)$ & \\
\hline
\end{tabular}
N. 
Table 7: Contemporaneous and lead-lag relations between financial cycle indicators and the FSS index, continued

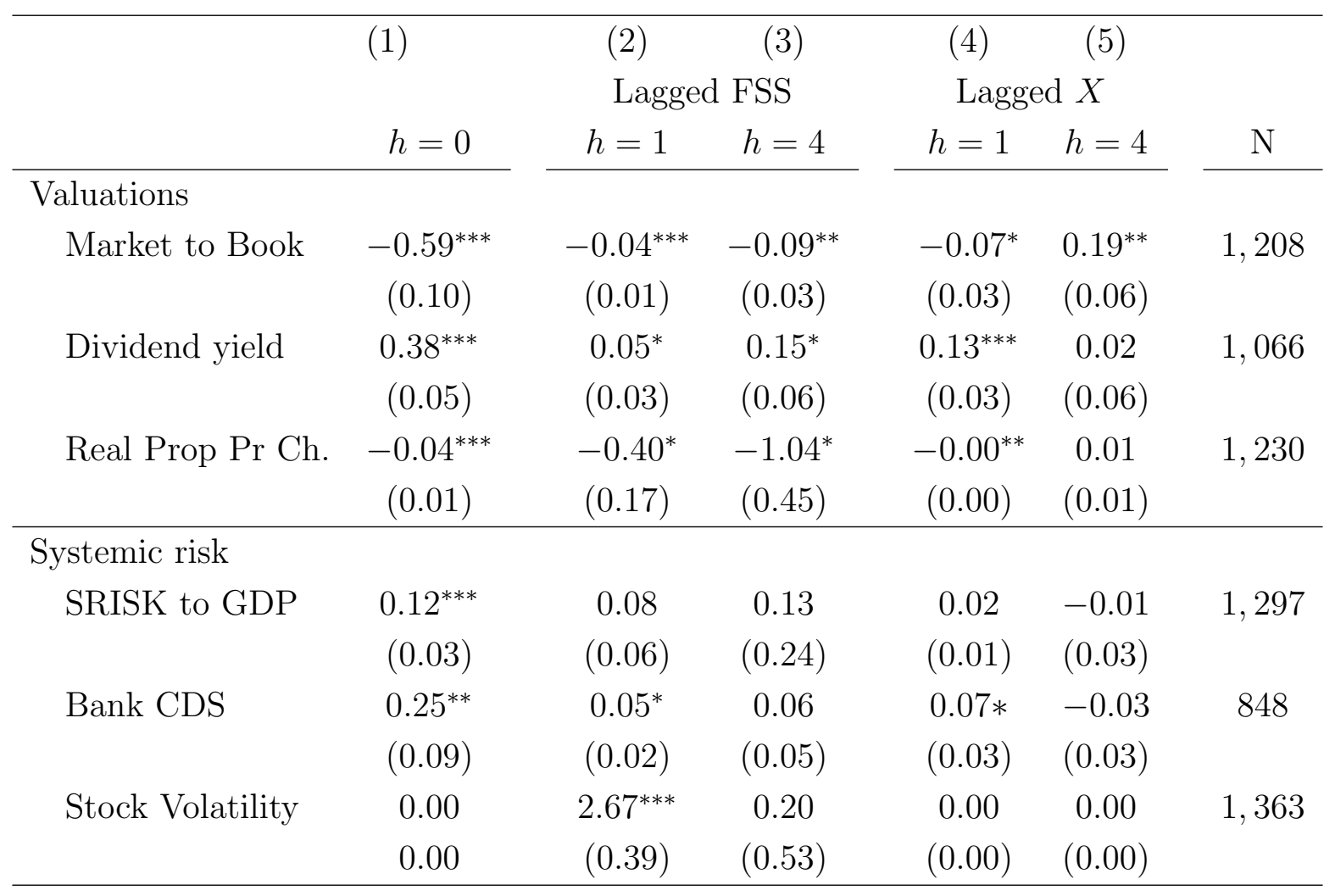


Table 8: The predictive power of FSS for systemic banking crises

This table summarizes the results from a panel-data probit model for the predictive power of FSS indexes for country-level banking crises. The first set of results, in panel (a), are those for the following univariate model:

$$
C_{i, t}=u_{i}+\beta_{F S S} F S S_{i, t-h}+e_{i, t},
$$

where $F S S_{i}$ represents each country's FSS index and $C_{i, t}$ is a dummy variable that takes the value of 1 when a banking crisis occurs in country $j$ at time $t$ and 0 otherwise. The banking crisis dummies are obtained from Laeven and Valencia (2013). Panel (b) shows the results for the following multivariate setting:

$$
C_{i, t}=u_{i}+\beta_{F S S} F S S_{i, t-h}+\beta_{C G D P} C G D P_{i, t-h}+\beta_{D S R} D S R_{i, t-h}+e_{i, t},
$$

where CGDP is the credit to GDP-to-GDP gap and DSR is the debt-to-service ratio for private nonfinancial corporations (see appendix A). In both panels, we report the estimated coefficients associated with each right-hand-side variable, as well as the standard deviations (in parentheses). ${ }^{*},{ }^{* *}$, and ${ }^{* * *}$ represent the usual 10\%, 5\%, and $1 \%$ significance levels. For each variable, we also report the area under the curve (AUC) as an additional measure of fit. An area closer to 1 indicates a stronger fit, while an area closer to 0.5 indicates a weaker fit.

\begin{tabular}{lcccc}
\multicolumn{5}{c}{ Panel (a). Univariate setting } \\
\hline & $h=1$ & $h=2$ & $h=3$ & $h=4$ \\
\hline FSS & $18.21^{*}$ & 16.32 & 3.32 & -7.25 \\
& $(8.82)$ & $(9.12)$ & $(9.26)$ & $(9.32)$ \\
AUC & 0.64 & 0.63 & 0.53 & 0.44 \\
\hline
\end{tabular}

Panel (b). Multivariate setting

\begin{tabular}{lcccc}
\hline & $h=1$ & $h=2$ & $h=3$ & $h=4$ \\
\hline FSS & $22.04^{*}$ & 19.84 & 2.97 & -11.39 \\
& $(9.78)$ & $(10.45)$ & $(11.48)$ & $(10.91)$ \\
AUC & 0.70 & 0.67 & 0.55 & 0.44 \\
Credit to GDP gap & 0.01 & 0.01 & 0.01 & 0.01 \\
& $(0.01)$ & $(0.01)$ & $(0.01)$ & $(0.01)$ \\
AUC & 0.66 & 0.65 & 0.64 & 0.63 \\
DSR, private nonfinancial & 0.02 & 0.01 & 0.02 & 0.02 \\
& $(0.02)$ & $(0.01)$ & $(0.01)$ & $(0.02)$ \\
AUC & 0.67 & 0.66 & 0.64 & 0.62 \\
\hline
\end{tabular}




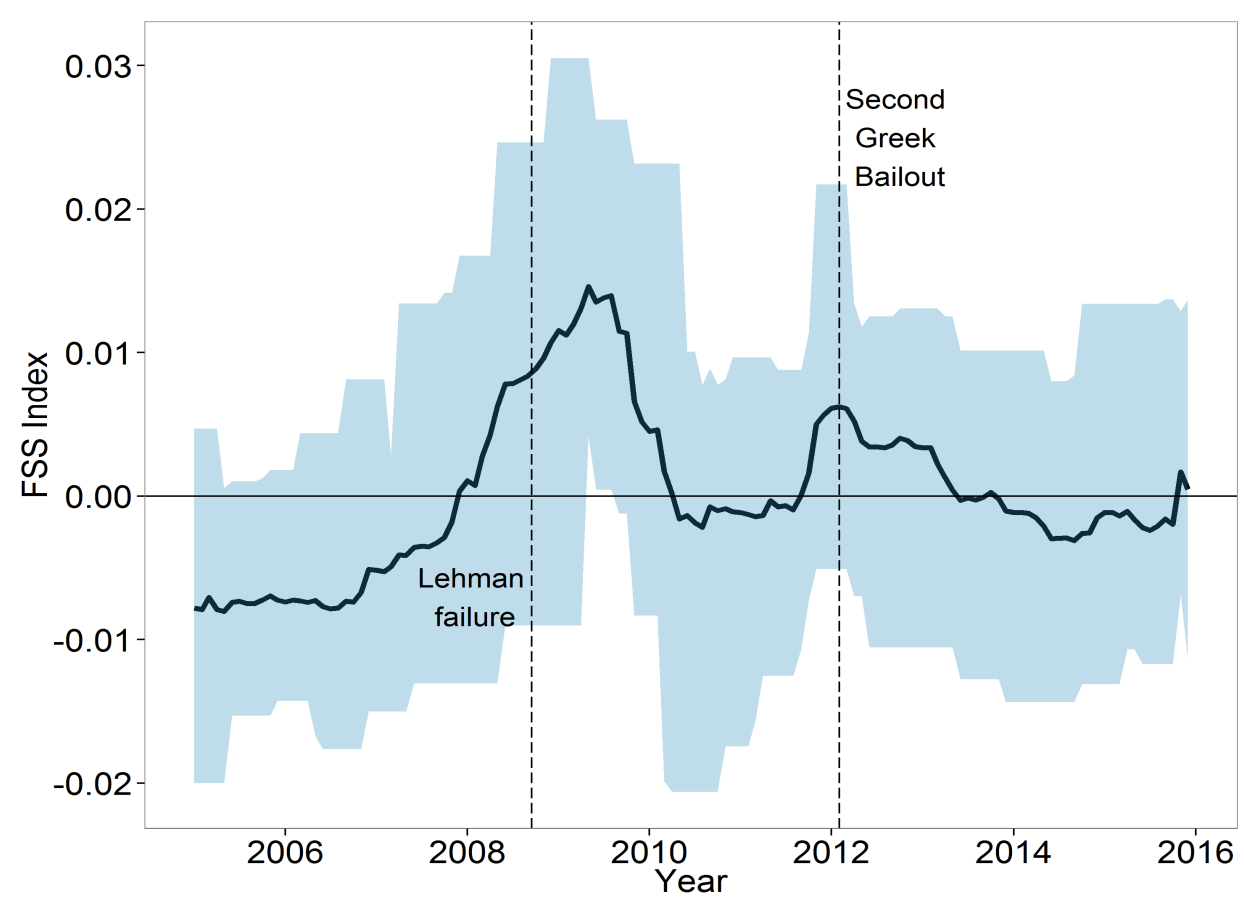

(a) All countries

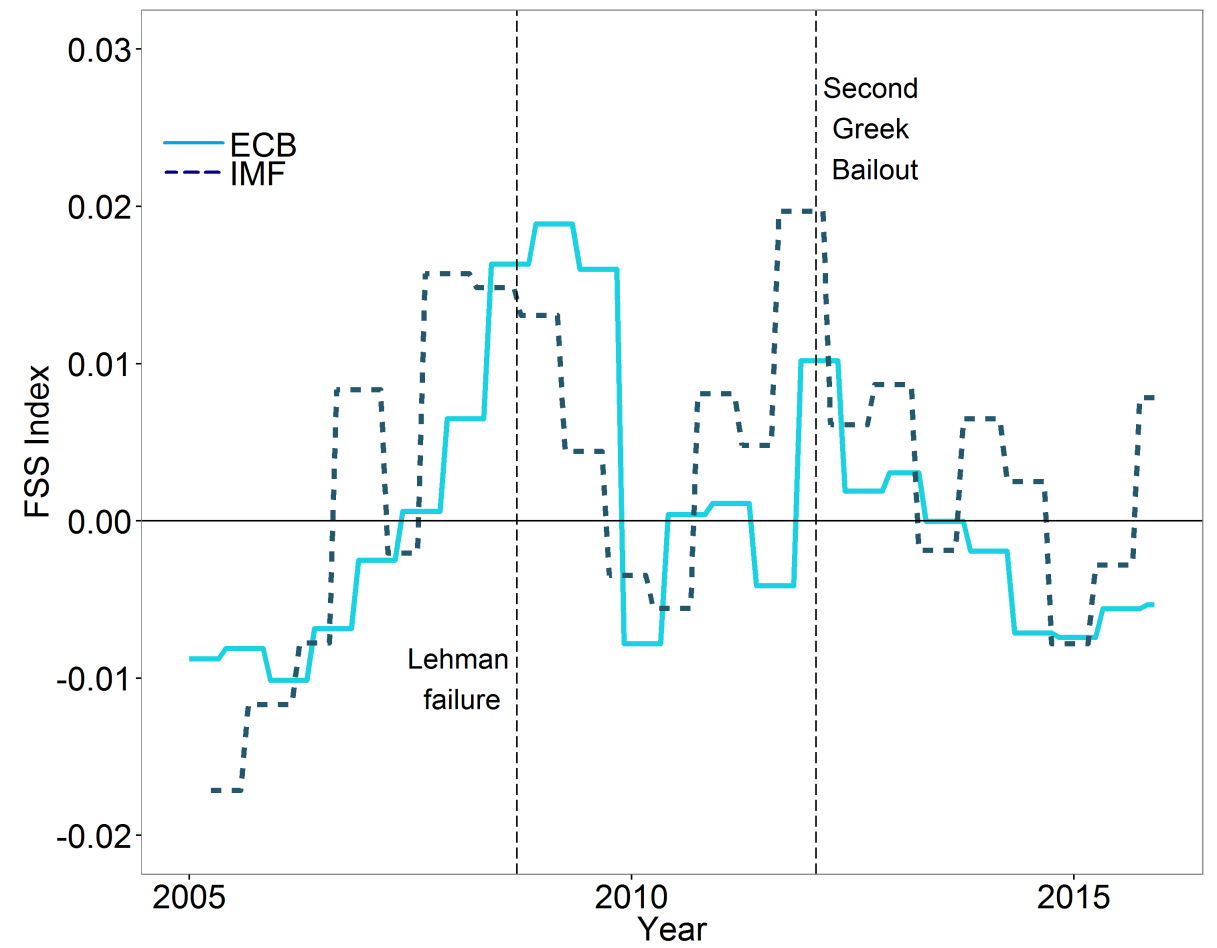

(b) ECB and IMF

Figure 1: FSS indexes

Panel (a) shows the equally-weighted average of all countries' demeaned FSS indexes (the bold line). We also show the range of demeaned FSS indexes for all countries in our sample (the shaded area). To calculate the quarterly average and range, for each country, we assume a step function to interpolate between any two dates with FSRs available. Panel (b) shows the demeaned ECB and IMF FSS indexes. 


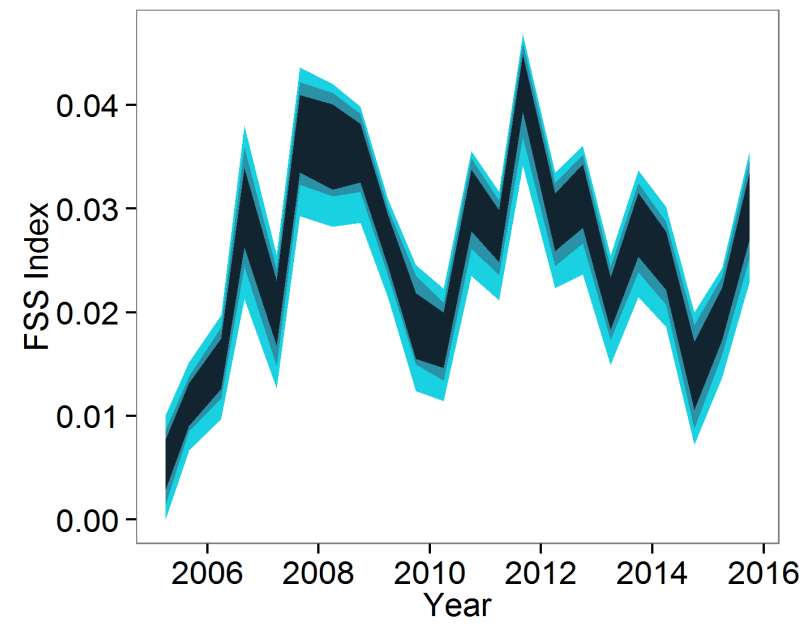

(a) IMF

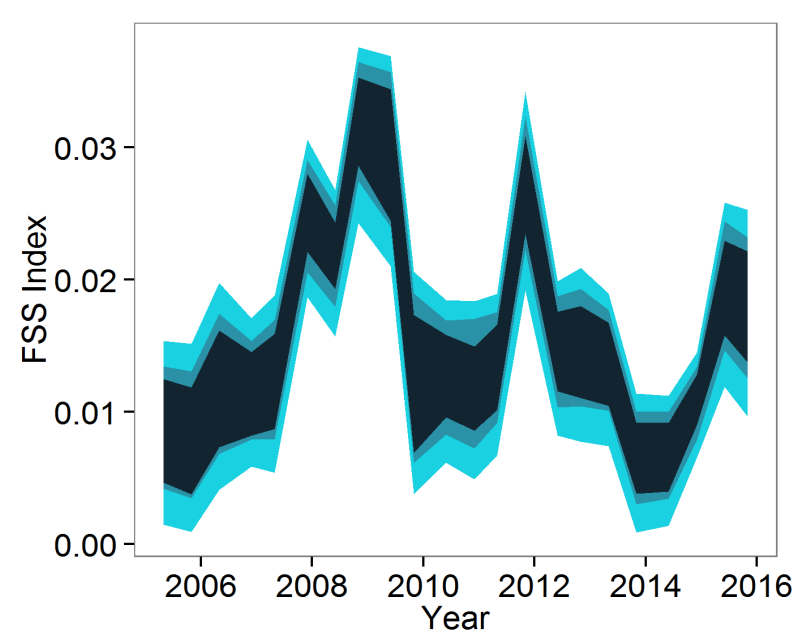

(c) Sweden

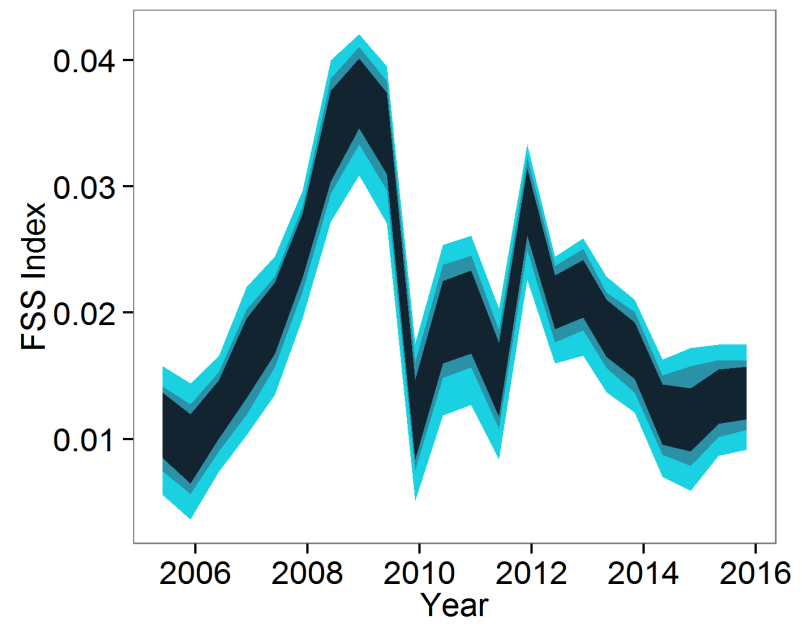

(b) ECB

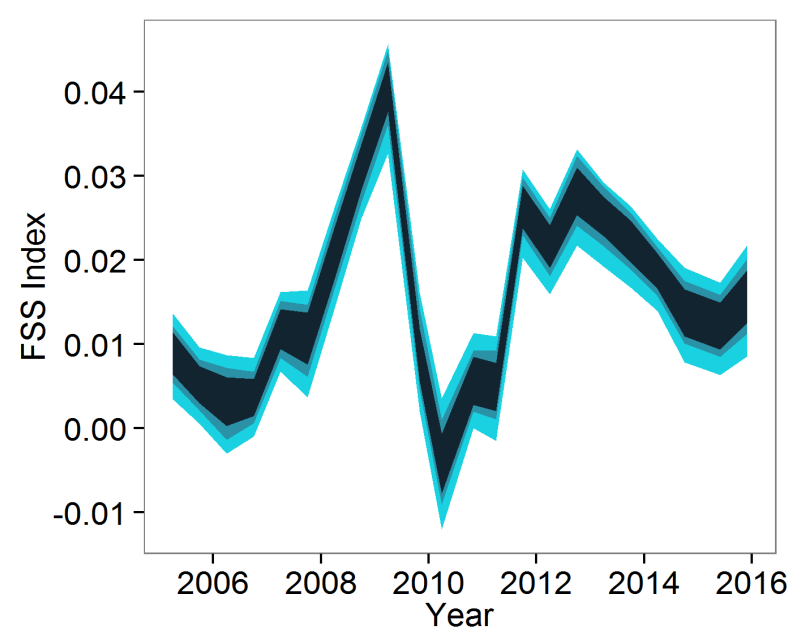

(d) Korea

Figure 2: Confidence intervals for the FSS index for selected countries and regions

This figure summarizes the results for the sensitivity of FSS indexes to the words in the dictionary. The shaded areas show 90 percent confidence intervals calculated by randomly removing 5 (dark blue), 10 (medium blue), and 20 (light blue) percent of the words in the dictionary for selected regions (IMF and ECB) and countries (Sweden and Korea). To calculate the intervals, the process of randomly removing words from the dictionary and recalculating FSS indexes is repeated 1000 times. 


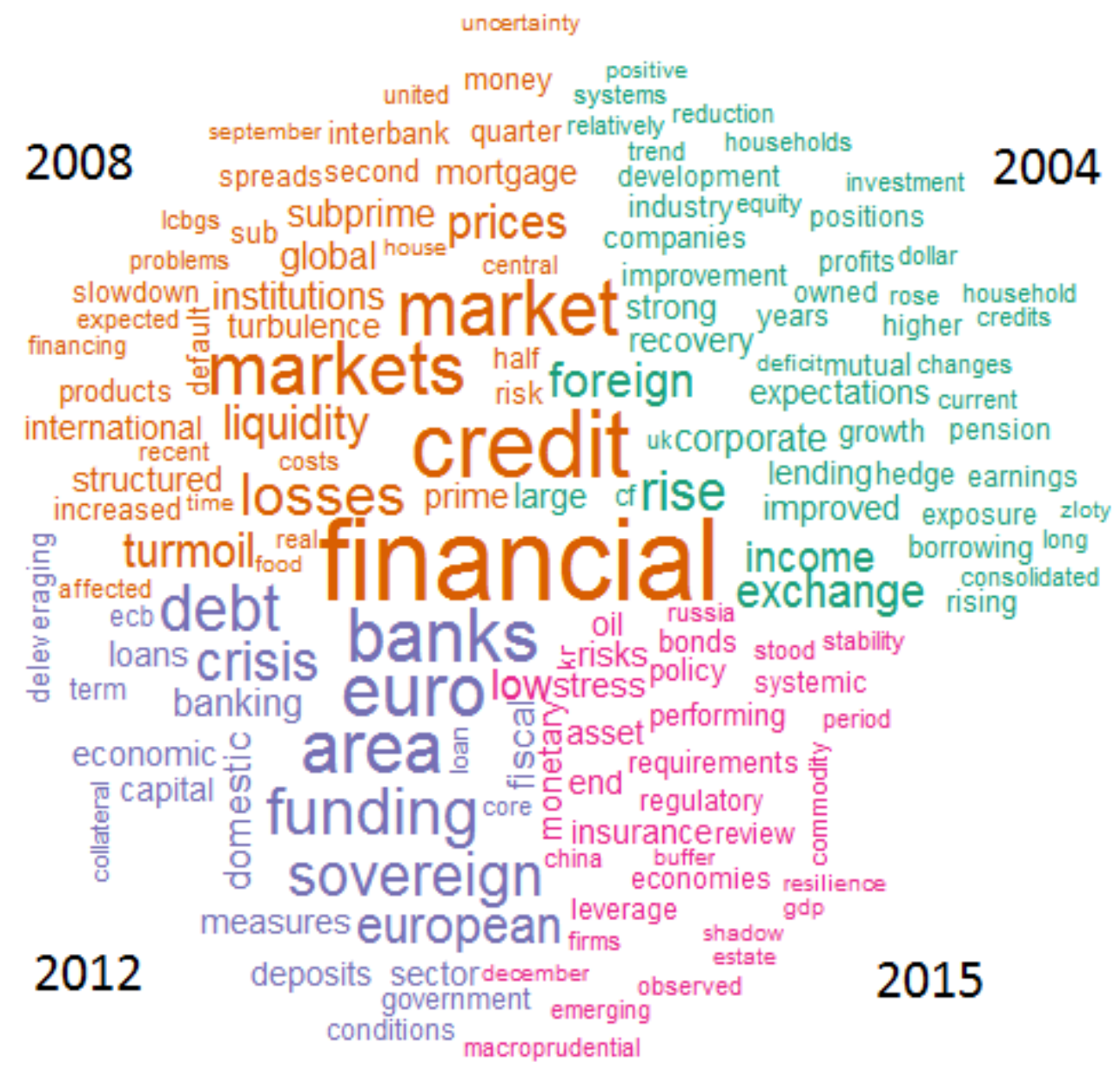

Figure 3: Word cloud

This figure shows a word cloud constructed from all FSRs available for the following years: 2004, 2008, 2012, and 2015. The size of the words is determined by their relative frequency of use, so larger words are more frequently used in each time period. 

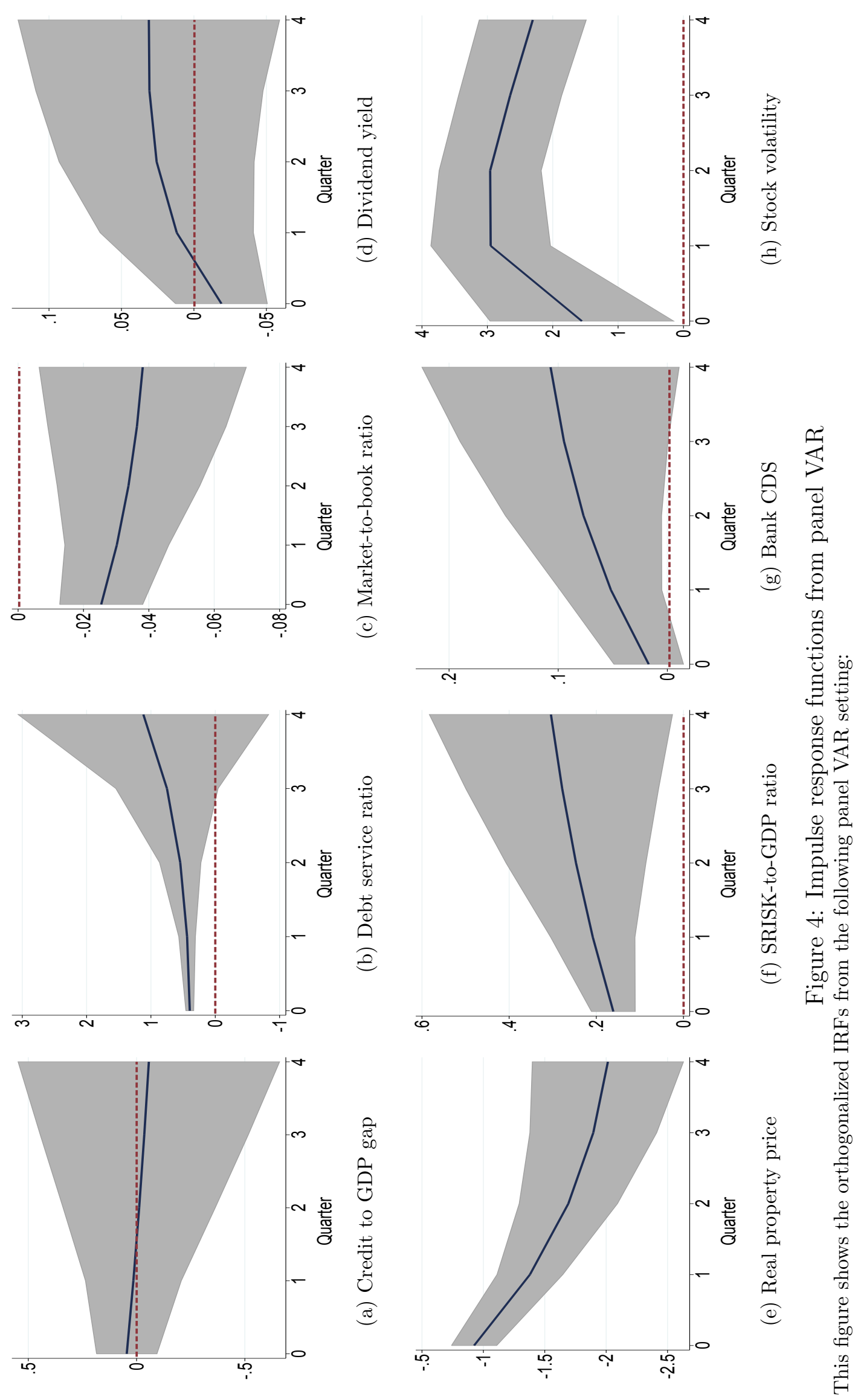

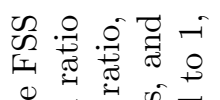

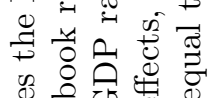

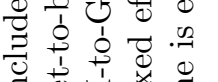

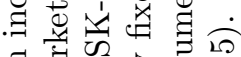

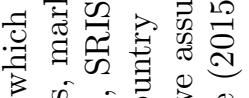

उ.

造.

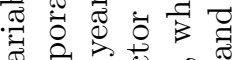

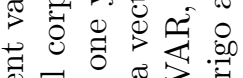

轨.

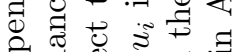

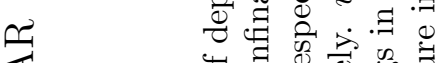

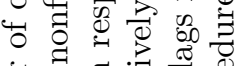

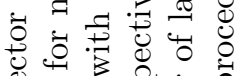

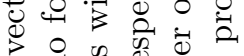

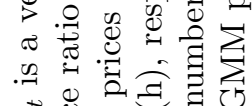

至

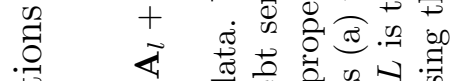

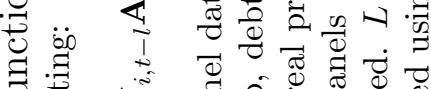

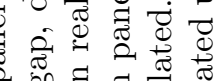

政 0

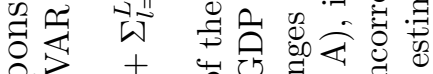

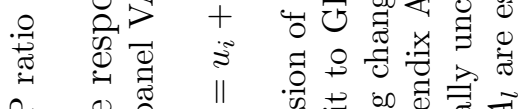

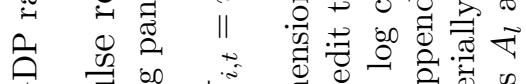

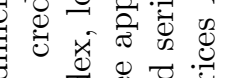

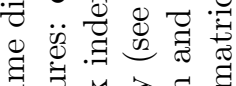

灵

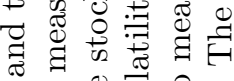

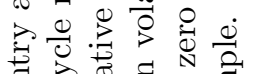

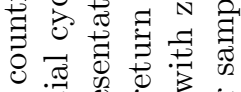

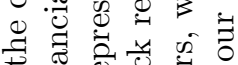

政

bo

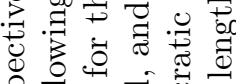

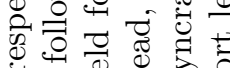

$\because \%$

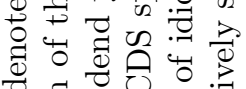

의

t

可

제

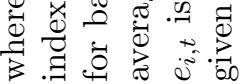



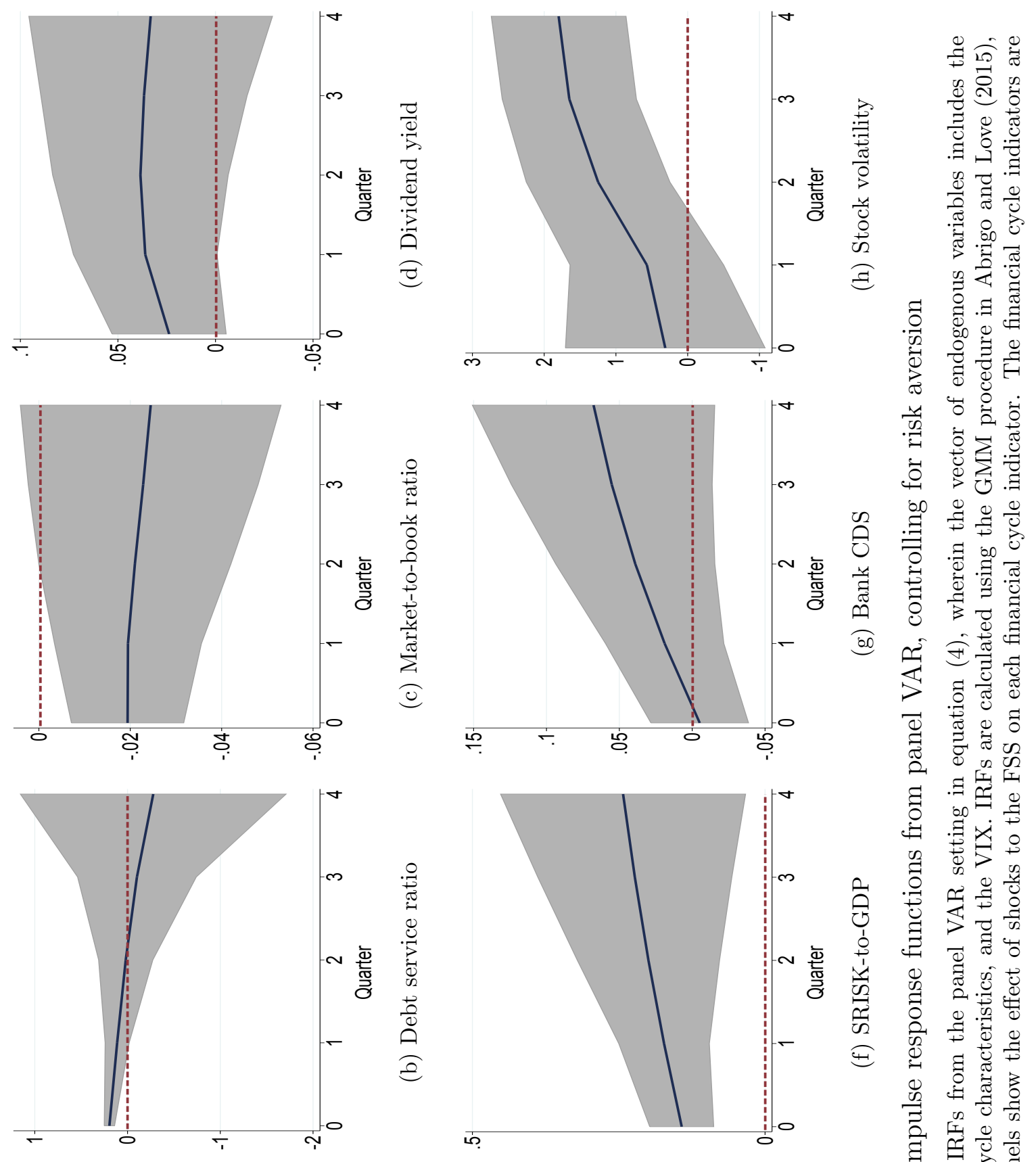

‥

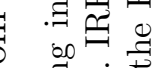

象
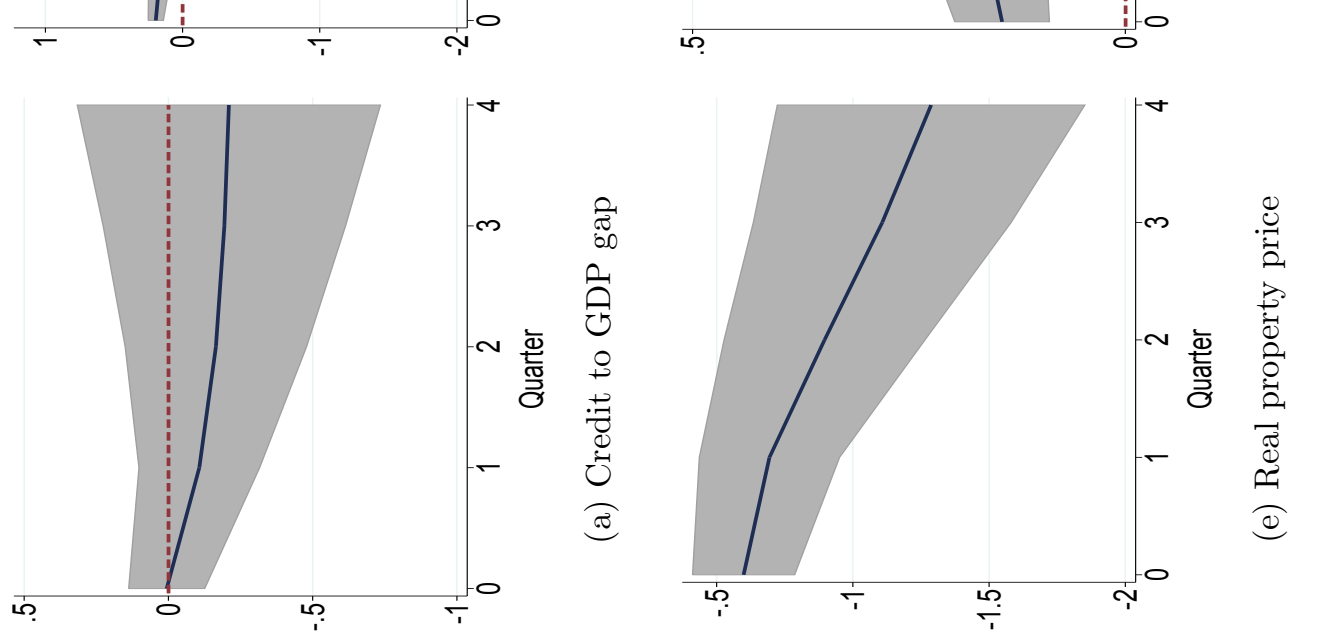

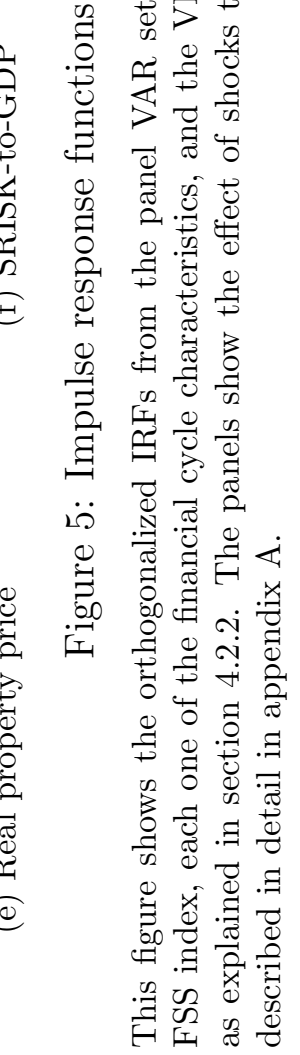



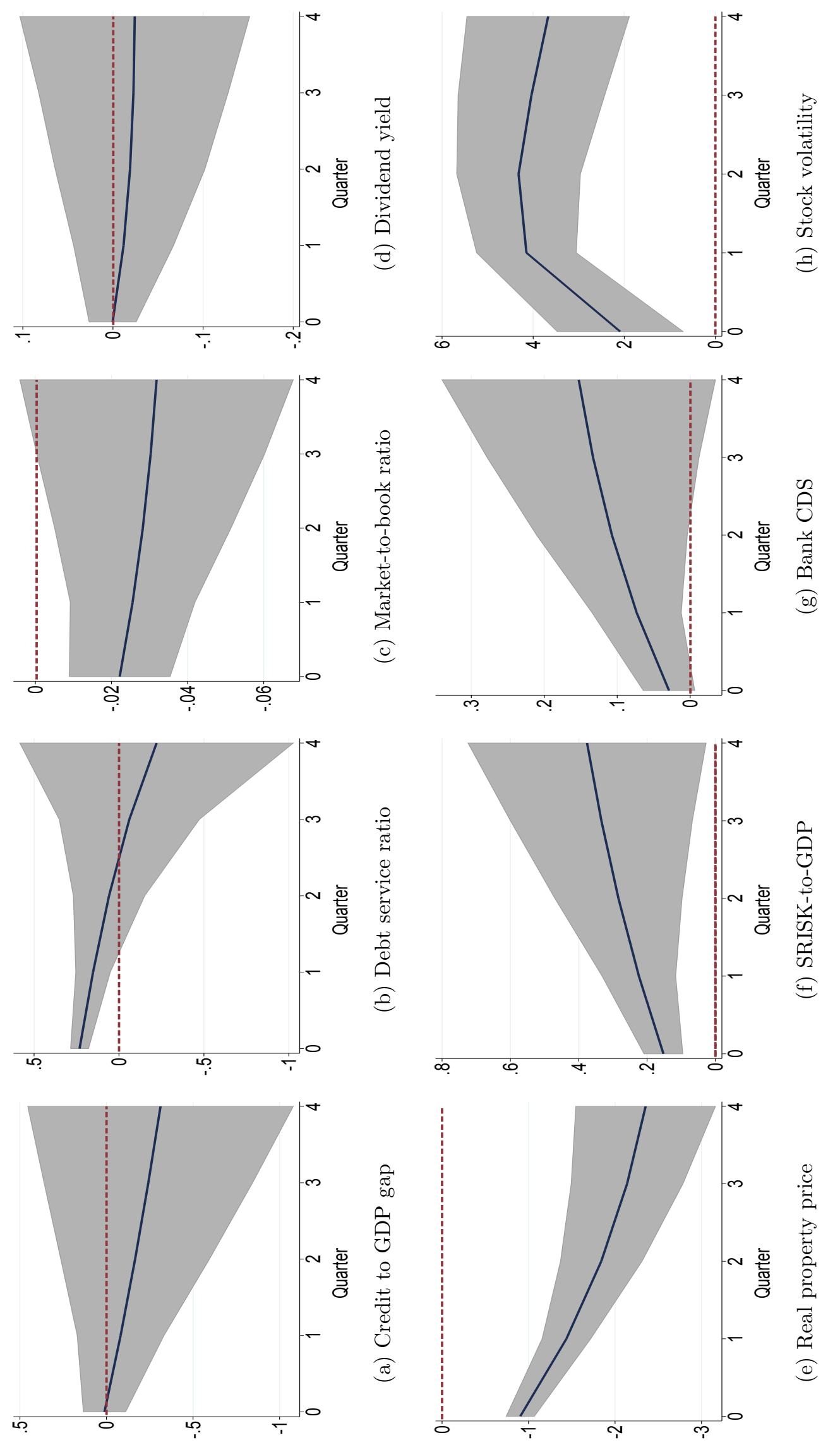

岁

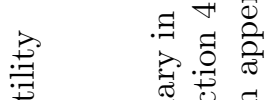

范.

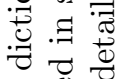

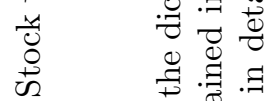

త $\quad$ क

:

疍 奈

.

$\circ$ ○

क

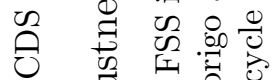

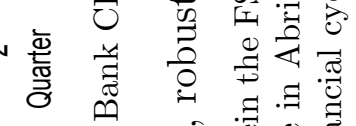

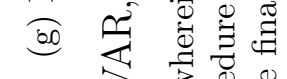

$>$ B

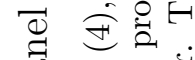

气ี

吾

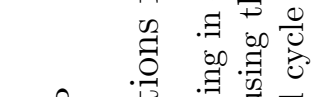

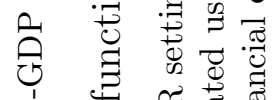

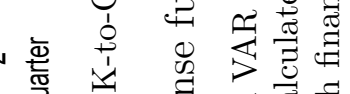

वे जू

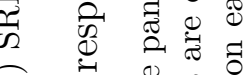

0

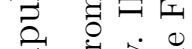

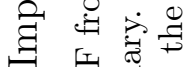

$\therefore$ 象。용

0.

สี

过:

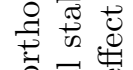

ठี.

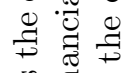

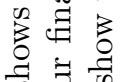

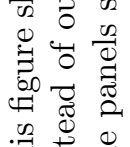

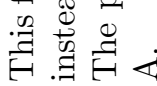



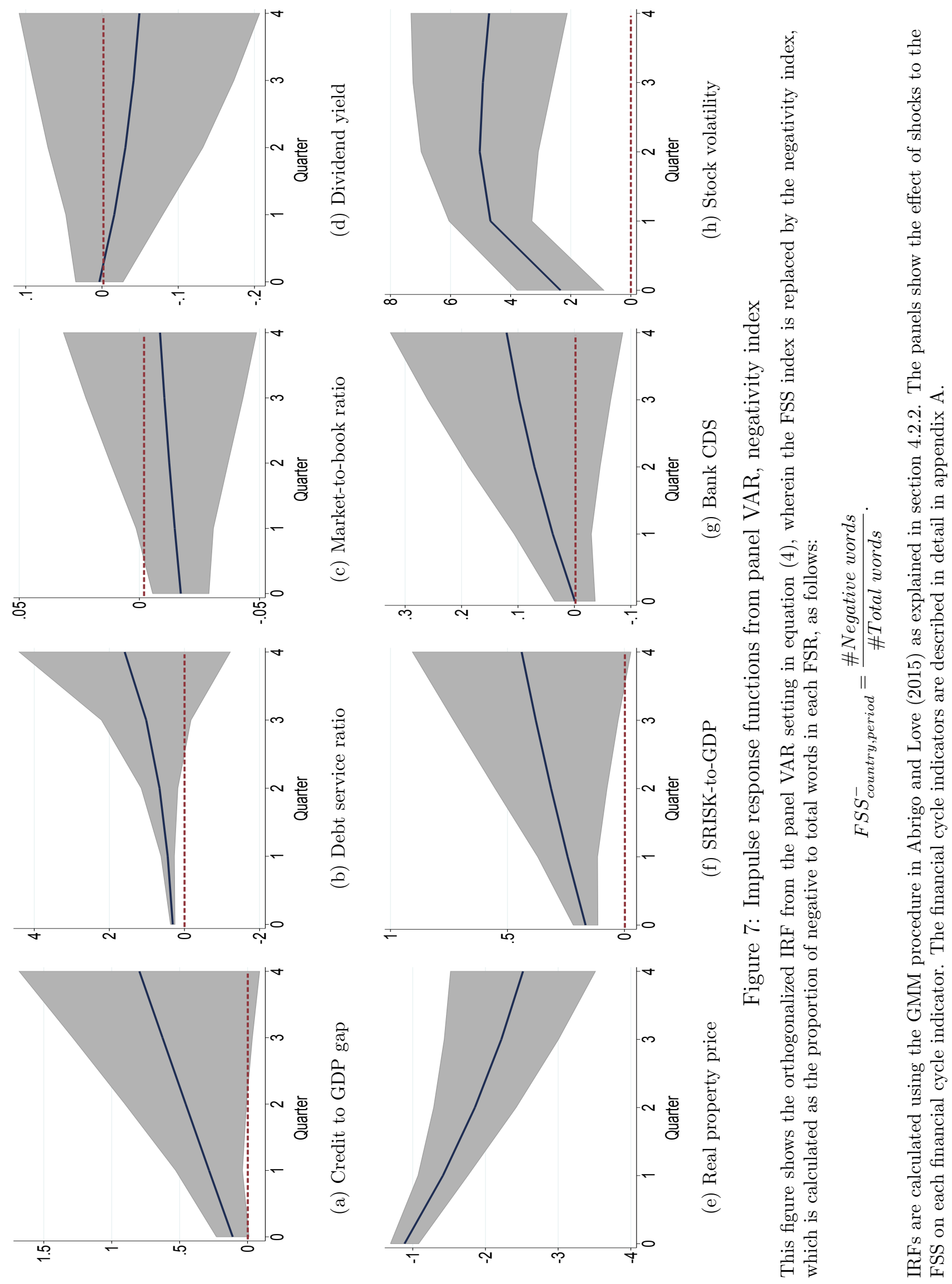

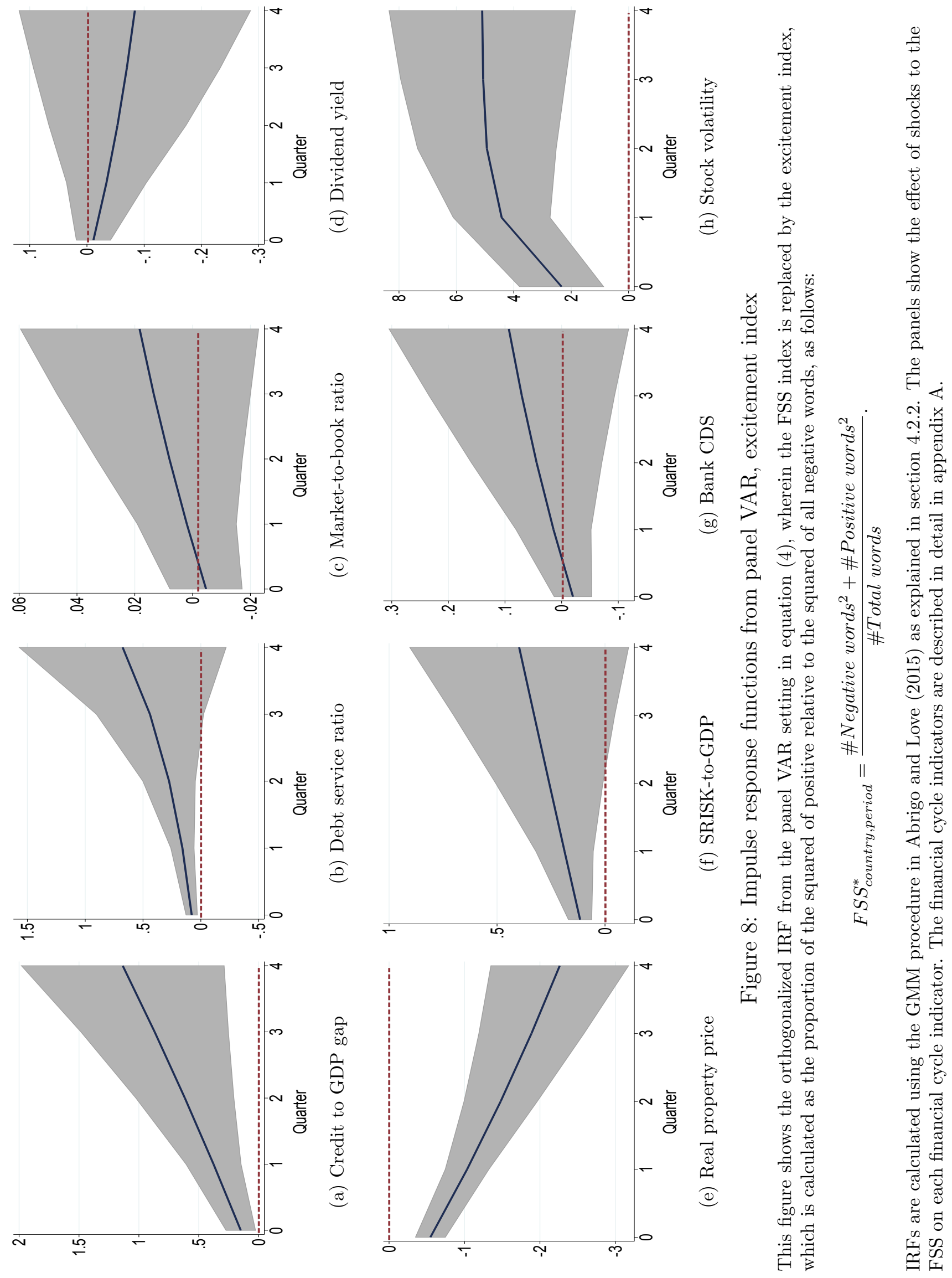